PONTES DE MIRANDA, FRANCISCO CAVAL CANTI. Tratado de Direito Privado. Rio de Janeiro Borsoi, 1956, v. 15; 1961, v. 34; 1965, v. 49.

REALE, MIGUEL. Exposição de Motivos do Anteprojeto de Código Civil (19 de março de 1973). In: Anteprojeto de Código Civil. Brasília: Departamento de Imprensa Nacional, 1973, p. 3-22.

O Projeto do novo Código $\mathrm{Ci}$

vil. São Paulo: Saraiva, 1999.

REQUIÃO, RUBENS. Curso de Direito Comercial. São Paulo: Saraiva, 1988, v. 1; 1987, v. 2.
Projeto de Código Civil. Revista de Direito Mercantil, Industrial, Econômico e Financeiro. São Paulo: RT, nº 17, nova série, 1975, p. 133-173.

SAMPAIO, PEDRO. Letra de Câmbio e Nota Promissória. São Paulo: Saraiva, 1975.

WEIGMANN, ROBERTO. Limpresa individuale a responsabilità limitata. In: GALGANO, FRANCESCO (org.). Atlante di Diritto Privato Comparato. Bolonha: Zanichelli, 1997, p. $195-$ 206

\section{Redes Contractuales: Conceptualizaciòn juridica, relaciones internas de colaboracion, efectos frente a terceros ${ }^{1}$}

Ricando Loxenretti

Professor da Universidade de Buenos Aires

\section{PRIMERA PARTE} Conceptualizaciòn juridica

\section{SUMÁRIO}

PRIMERA PARTE :

Conceptualizaciòn juridica

I) Finalidad economica

II) Teorias juridicas sobre las redes contractuales

III) La teoria sistemica

SEGUNDA PARTE : Relaciones internas

I) Elementos tipificantes y Caracteres:

II) Contrato y sistema

III) El control a traves de la red

IV) Efectos entre las partes: deberes de proteccion del sistema

TERCERA PARTE : Relaciones Externas

I) Efectos frente a terceros:

\section{I) Finalidad economica}

1. La oferta asociada y los productos complejos

uando una empresa que presta dinero y otra que vende heladeras, deciden aunarse para mejorar su posicionamiento en el mercado, prestando dinero y vendiendo heladeras a los consumidores, tenemos al menos tres cumulos de relaciones. Entre ambas empresas, aunque no exista ningun convenio, aunque no se de una oferta unificada, hay una colaboracion que se obtiene mediante la "convivencia de contratos distintos": si una presta dinero y la otra vende heladeras por

1. Versão ampliada da conferência ministrada nas Jornadas Preparatórias do XVII Congresso Argentino de Direito Civil, organizadas conjuntamente pelo Mestrado em Direito-UFRGS, Faculdade de Direito da UFRGS e Faculdade de Direito da Universidad Nacional del Litoral, Santa Fé, Argentina, de 17 a 19 de setembro de 1998, no Salăo Nobre da Faculdade de Direito, UFRGS, Porto Alegre. 
separado, brindaran menos satisfaccion que si ponen al alcance del cliente un producto complejo y completo. A renglon seguido tenemos las relaciones que se dan entre es tas empresas y el cliente, que pueden se dos o tres. Seran dos relaciones si las em presas unifican la oferta; seran tres vinculos si las empresas no ofertan unificadamente celebrando contratos distintos con el cliente.

Frente a este tipo de ofertas, los consumidores tienen algun beneficio por el hecho de estar juntos: compran el bien màs barato porque hay costos que se prorratean entre el grupo, obtienen mejores financiaciones porque representan un volùmen econòmico màs interesante para el financista, y muchas otras ventajas.

Similares apreciaciones podemos hacer en relacion a los productos complejos, sistemas contractuales de ahorro, o las tarjetas de credito. ejemplos.

Veremos seguidamente algunos

\section{Redes de consumidores: reglas de circulaciòn ordenada de contratos}

Si alguien compra un bien habrà una relaciòn de cambio, al igual que si solicita un crèdito. Pero la situaciòn cambia si la compra la hace a travès de una red de usuarios de tarjetas de creditos, o de un club de usuarios, o de un sistema de ahorro previo. Si alguien celebra un contrato medico, es una relaciòn de cambio, pero si es integrante de un "sistema de medicina prepaga",la situaciòn varia.
¿Por què es distinta? - Los contratos siguen siendo autònomos y las relaciones individuales, pero el estar juntos les da una tonalidad especial. - A las relaciones de cambio se le superpone un vìnculo conceptualmente inasible por ahora.

Algo similar sucede con los automòviles. Tenemos un concepto bastante claro del automotor y con ello nos desenvolvemos bien. Pero si vemos muchos automotores circulando en un ciudad, provocando un caos en el trànsito, debemos establecer reglas de circulaciòn que eviten la congestion. Estas reglas se vuelven imprescindibles para la existencia de los automotores circulando masivamente, de modo tal que el concepto del automotor evoca como consecuencia inevitable el de las reglas de circulaciòm.

Tambièn puede haber congestion contractual por la circulaciòn masiva de ellos; puede haber un tràfico desordenado que desequilibre el sistema.

¿Que sucede si un contratante reclama algo justo para èl pero excesivamente costoso para el conjunto?, esos costos los soportarà el sistema, y cada uno de los contratantes.

La causa contractual permanece indemne, pero la causa sistematica se desequilibra.

\section{La metafora del amacenero, \\ la cadena y la red de \\ distribucion:}

No hace muchos años nos valìamos de la "metafora del amacenero", que nos servìa para comprender el fenòmeno de los almacenes de ramos generales; vendian toda clase de productos de escasa elaboraciòn, porque los podian comprar directamente de sus productores, en el campo cercano al pueblo. Eran propietarios de lo que vendìan, y abarcaban una gran variedad de productos.

\section{Era un personaje importante.}

Cuando se comenzaron a vende productos màs elaborados, hubo que recurrir a fabricantes de otras zonas, y a los distribuidores que èstos señalaban. Comenzaron a surgir sistemas de comercializacion que nos llevaron a la "metafora de la cadena", que nos permite entender còmo un fabricante vende a un mayorista, y èste al minorista, mediante negocios ventas sucesivas encadenadas.

El "almacenero de ramos generales", se vuelve "minorista", y su figura se adelgaza; muchas veces no es dueño sino que recibe en consignaciòn, en suministro, depende de lo que le manden o no, de la calidad decidida por otros. Se produce asì un fraccionamiento de conductas en la cadena: uno fabrica, otro distribuye, otro vende $y$, aunque frente al consumidor se pretende diluir estas diferencias, las mismas se muestran perennes en las relaciones internas.

La cadena es el enlazamiento de un miembro inicial, otros intermediarios y uno final que se relaciona con el adquirente. $\mathrm{La}$ cadena es lineal, vertical segùn algunos autores. Lo caracterìstico es que se advierte en ella una sucesiòn temporal de actos juridicos, del uno al otro y asì sucesivamente.

Otro fenòmeno distinto surge cuando hay muchos distribuidores, o muchos fabricantes, producièndose un ensanchamiento de uno de los eslabones de la cadena. El problema no es ya la circulaciòn del producto o servicio a travès de actos sucesivos, sino la actuaciòn de un conjunto en forma simultànea.

Pasamos entonces a la "metafora de la red", que plantea cuestiones diferentes.

Si una empresa vende a un distribuidor, estamos ante una relaciòn de cambio. Pero si arma una red de distribuidores, todos deben actuar coordinadamente y, si bien son contratos individuales, autònomos, hay algo que los une y que requiere que funcionen conjuntamente. Por otra parte, la red es oscura y compleja en sus relaciones: los productos y servicios pueden circular a travès de ella sin que existan transferencias dominiales, utilizandose contratos de comodato o suministro. Pueden existir miembros antiguos y nuevos, privilegiados 0 no. Pueden plantearse incluso conflictos internos como los relativos a zonas de distribucion, o bien frente a terceros, como la responsabilidad laboral o por daños.

Finalmente, retornamos a un almacenero de ramos generales sofisticado: el hipermercado de consumo.

En la cadena hay una sucesiòn de actos; en la red una simultaneidad; pero en ambos casos hay un titular del interès y una delegaciòn gestoria.

En el hipermercado de consumo hay, a semejanza de la red, una actuaciòn simultànea, pero a diferencia de ella, hay una finalidad comùn, un interès compartido; es un almacèn de ramos generales ampliado y con mùltiples participantes. En el 
hipermercado hay una empresa que se dedica a la explotaciòn del shoping center. Esta empresa celebra contratos de locaciòn con otras que instalan allì sus negocios. Examinada la relaciòn individual, existe una causa de cambio, mediante la cual se cede el uso y goce de un local contra el pago de un precio. Pero lo cierto es que la multiplicidad de relaciones locativas, conexas entre si, tiene algùn efecto. Naturalmente, alquilar un local para instalar un negocio, es un hecho econòmicamente distinto si se lo hace en un shoping o fuera de èl. El hacerlo dentro del hipermercado significa participar de una empresa comùn. Surge asì un vinculo asociativo que se superpone con la relaciòn de cambio, modificando algunos de sus aspectos.

Esta superposiciòn no es asfixiante, de modo tal que sigue siendo una relaciòn de cambio, pero modificada en algunos aspectos por el vìnculo asociativo que la entorna. Por ello, es una mera conexidad y no un vinculo atipico o tipico que represente una ùnica empresa comùn. La diversidad subsiste, pero se homogeneiniza en algunos aspectos decisivos para la protecciòn de terceros y para la subsistencia del sistema.

El mantenimiento de la empresa se sustenta en diferentes aspectos: existe un lugar y espacios de utilizaciòn comùn; gastos de mantenimiento y subcontrataciones, tambièn compartidos. Una instalaciòn del shoping planificada aprovechando espacios, diversificando los productos y servicios ofrecidos, una buena coordinacion de los gastos comunes, son claves del exito del mantenimiento de la empresa.

Frente a los terceros, publicidad se realiza unificadamente, incluso con fondos comunitarios. Se suelen establecer precios competitivos acordados, horarios extendidos, promociones especiales.

De esta manera, no esta diversificada la titularidad del interès y la ejecuciòn, sino que, por el contrario, hay una empresa comùn.

\section{Coordinadores de servicios y de productos: La subcontrataciòn masiva}

Una obra social o una empresa de medicina prepaga que prestan servicios mèdicos, generalmente no lo hacen por sì mismos, porque es excesivamente costoso tener servicios propios en toda la zona de cobertura. Por ello, puede contratar los servicios de clinica con el medico, los que requieren estudios màs complejos con un centro de diagnostico, los de cirugia con un sanatorio, los de emergencia con una empresa dedicada a ello. En otros casos puede valerse de un intermediario como una empresa o una asociaciòn profesional. A su vez, todo ello se repite en distintas zonas geogràficas en las que se brindan servicios.

De tal modo, surge una red compleja que, necesariamente debe actuar en forma coordinada frente al paciente.

Algo similar ocurre con los productos. Es habitual que una empresa que es fabricante de un producto subcontrate con otros la fabricaciòn de partes o la prestaciòn de servicios. Comenzarà contratando el servicio de vigilancia, luego la administraciòn, la computacion, elaboraciòn de partes del producto.

El resultado final puede ser un fabricante que sea el coordinador de un grupo de fabricantes y prestadores de servicios; son personas jurìdicas distintas que celebran contratos disìmiles.

\section{Comunidades reales}

Otro fenòmeno de interès lo constituyen los agrupamientos de propietarios. Quien compra un departamento, o adquiere una parcela en un cementerio privado o se adhiere a un sistema de tiempo compartido o un club de campo, puede pensar que se halla suficientemente protegido porque es titular de un derecho real.

$\mathrm{Al}$ poco tiempo descubrirà que la contrataciòn de las expensas, de la policia o la mayoria de los gastos, no son aspectos que pueda decidir como lo harìa cualquier propietario. Son determinados por un grupo que a su vez es dominado por un subgrupo, o bien por una empresa que administra.

De tal modo se encontrarà muchas veces cautivo de las decisiones que otros toman y que tendrà que aceptar. El costo de separarse serà màs alto que el de mantenerse dentro del grupo.

Se asiste a un fenòmeno de contractualizacion de la propiedad derivada de la separacion entre explotacion y titularidad.

Hay muchos bienes en los que resulta economicamente importante la explotacion y el uso de los mismos, subalternizandose la titularidad dominial. privada, la construccion de obras comunes,

El problema no es la relacion de inmediatez entre un sujeto y el bien, ni tampoco es relevante la intromision de terceros o la proteccion erga omnes.

El problema fundamental es la relacion entre una empresa que lucra con la explotacion de los bienes y el publico consumidor. La empresa se ocupa por si misma de los problemas de proteccion frente a terceros, y sin embargo no es la titular del dominio. Establece reglamentos de uso sin que esta facultad sea una emanacion de un derecho real.

El consumidor resulta un titular dominial invalido, a quien poco le sirve la invocacion del derecho real.

Surge un grupo de titulares dominiales con vinculos de conexidad contractual y una temàtica tipica de la contrataciòn de consumo.

\section{El aseguramiento individual y \\ la comunidad de riesgos}

La doctrina que ha investigado el contrato de seguro ha encontrado dificultades para distinguir la relacion asegurado-empresa de la comunidad de contratos que son necesarios para que el sistema funcione.

Todos los autores coinciden en que esa mutualidad permite el funcionamiento de la empresa asegurativa al facilitar el fraccionamiento de riesgos homogeneos. A este aspecto se lo considera dentro de la "economia" del seguro o dentro de los ele. mentos "tecnicos" ?

2. por ej conf en la doctrina francesa LAMBERT FAIVRE, Y, "Droit des Assurances", Dalloz, Pariz, 1995. 
Hay coincidencia entre los economistas y abogados sobre la existencia de ese elemento tecnico y su necesidad, pero dentro de la ciencia juridica debemos explicar cual es su importancia y significado.

En su reciente y magnifica obra Stiglit $z^{3}$ indica que la relevancia de ello radica en que se deben aplicar e interpretar las normas que delimitan el riesgo de modo que hagan posible esta comunidad de riesgos. Asi, sostiene que las condiciones generales que determinen con rigor el riesgo, las que consagren la suspension automatica de la cobertura para el caso de falta de pago, las que establezcan sanciones para la inobservancia dolosa de las cargas informativas, deben ser interpretadas literalmente a fin de sostener la comunidad de riesgos.

Estas clausulas, que examinadas en un contrato bilateral podrian afectar la relacion conmutativa, encuentran su razon en la proteccion del sistema que permite la celebracion y funcionamiento del contrato, y por lo tanto no serian abusivas.

La frontera no es sencilla de establecer, ya que en el derecho de proteccion de los consumidores se avanza en la descalificacion de las clausulas abusivas. En este camino se consideran que lesionan la reciprocidad de las obligaciones algunas disposiciones que encuentran su explicacion en la comunidad de riesgos; ello es frecuente en los contratos de seguros de salud con referencia a las exclusiones de enfermedades, carencias, y otros aspectos similares.
Llegados a este punto, debemos suplementar las nociones economicas y tecnicas del negocio asegurativo con intrumentos juridicos que aporten criterios de solucion.

En este aspecto, nos parece que la solucion es relacionar contrato y sistema, y la causa del contrato con la causa del siste ma.

\section{Consecuencias juridicas}

Para extraer consecuencias juridicas de estos nuevos encadenamientos, hay que ordenar los problemas que producen.

La union de contratos es un medio que se utiliza para la satisfaccion de un interes, que no se puede realizar normalmente a traves de las figuras tipicas existentes. De ello debemos deducir que hay una parte que busca una satisfaccion y otra que intenta satisfacerla mediante un encadenamiento contractual.

Habra que discernir entre las relaciones juridicas que surgen entre los participantes de los distintos contratos que colaboran entre si a fin de dar satisfaccion, y las que se dan entre estos y el que busca la obtencion del interes. En este ultimo caso habra que distinguir aquellos casos en que se trata de relaciones de consumo, por su normativa especial.

Desde el punto de vista de las empresas oferentes, los contratos coligados son un asunto de colaboracion; ya no una colaboracion asociativa que se logra a traves de un contrato, sino de varios.
Desde el punto de vista del cliente, es un problema de relacionamiento: iestan relacionados estos contratos?; ies posible pensar en que las viscisitudes de uno estan sujetos a la condicion de que el otro se cumpla?; i se puede vincular a los sujetos distintos de contratos tambien dispares, por una demanda de responsabilidad?

El estudio de estos aspectos nos lleva por caminos novedosos del derecho de los contratos.

\section{II) Teorias jurìdicas sobre las redes contractuales}

Aunque el tema es novedoso en la doctrina contractualista internacional, existen algunas aproximaciones teòricas destinadas a captar el fenòmeno.

\section{La tesis de los contratos relacionales}

En el derecho anglosajòn se ha desarrollado la teoria de los contratos relacionales ${ }^{4}$, que se refiere a dos fenòmenos simultàneos: los vinculos de larga duracion y las redes contractuales. La teorìa contrac tual debe modificarse para captar las relaciones flexibles que unen a las empresas en la economìa actual y tener en cuenta que estos vìnculos se hacen con perspectiva de futuro. La teoria clàsica contempla al contrato como algo aislado y discontìnuo, con un objeto definido que hace "presente" lo que las partes haràn en el futuro (por ejemplo, comprar y vender una cosa).
El contrato actual, en cambio, presenta un objeto vacìo, porque en realidad se pactan procedimientos de actuaciòn, reglas que uniràn a las partes y que se iràn especificando a lo largo del proceso de cumplimiento. Los vìnculos de larga duraciòn tienen un caràcter procesal, en el sentido de que el objeto no es una prestaciòn consistente en un dar o en un hacer determinado, sino determinable.

En el campo de las "networks" el contrato es una relaciòn entre empresas basada en la cooperaciòn. Se trata de vìnculos mùltiples basados en la confianza entre los agentes para lograr una metodologìa de producciòn flexible, que es lo que exige la economì actual. De modo que es esa confianza o cooperaciòn el elemento que une a esas redes.

Resumiento: se destaca al contrato como un conjunto de reglas que establecen comportamiento procedimentales para lograr un resultado flexible, basado en la cooperaciòn de un conjunto de agentes econòmicos.

Esta teorìa està basada en una aproximaciòn sociològica al tema y es descriptiva, razòn por la cual se le puede criticar que no aporta elementos para resolver el problema. No se advierte què efectos produce esta cooperaciòn, màs allà de los ya conocidos.

\section{El contrato marco de base asociativa basado en el interes comun}

En otra elaboraciòn, a nuestro juicio màs sofisticada, se trata de describir el

\section{STIGLITZ Ruben "Derecho de Seguros", Bs.As, Abeledo Perrot, 1997, T.I, pag.25}


fenòmeno y sacar algunas consecuencias del mismo, a partir de tesis conocidas, como el contrato marco, su naturaleza asociativa y la nociòn de interès comùn 5 .

En las redes hay un contrato marco como medio para alcanzar fines individua les y comunes. Por ejemplo, en las redes de franquicia o en la concesión, hay relacio nes bilaterales entre el franquiciante y e franquiciado, que representan los objetivo individuales. Ademàs, existen relaciones entre todos los miembros de la red, porque saben que obtienen de ella un beneficio adicional, que es el incremento de la distribuciòn y de las ventas.

El contrato marco regula el aspecto comùn de las redes.

Este contrato marco tiene un caràcter asociativo. No es una sociedad, porque hay empresas independientes entre sì, y no hay un beneficio comùn a repartir Las ventajas que se derivan de funcionamiento en red, van directamente a los que la integran, y no a un fondo comùn que luego se reparte.

Ese caràcter asociativo existe porque hay un interès comùn, que existe cuando una parte contratante posee interés personal y directo en la obligación de la contraparte. Una de las partes obtiene satisfacciones indirectas a travès de la prestaciòn que realiza la otra, sin que exista un vìnculo de cambio. De esa actuación concertada deviene una utilidad que exce de la nociòn de contraprestacion.

ECHEBARRIA SAENZ, Joseba A., "El contrato de franquicia-Definiciòn y conflictos en las relaciones internas", Editorial McGrawHill, Madrid, 1995, pag 161, y sssostiene que la franquicia serìa entonces "un contrato dotado de fin o interés común y ello nos permite su ubicación entre los contratos asociativos o de organización en sentido lato, factor de extremada importancia, puesto nos permitirá la traslación analógica de principios propios del contrato societario in genere". En función de ello, se podría proponer la aplicabilidad de principios y preceptos societarios que expresen la articulación o regulación de intereses convergentes, sin llegar a constituir normas de configuración estrictamente societaria o de regulación estatutaria de la figura del socio, entre ellas:

? La obligación de lealtad reforzada.

? El derecho de información y control que asiste al partícipe de la unión

? La concepción de las facultades de dirección comercial como "competencia reglada" informada por el fin común y no como derecho en sentido propio.

A pesar de que constituye un avance respecto de la anterior, esta tesis sigue el modelo societario, y a nuestro juicio, no capta algunos elementos realmente novedosos que aportan las redes.

\section{Grupos de contratos unidos por una operaciòn econòmica}

Muchos autores han tratado el tema de los contratos coligados señalando que hay "una pluralidad coordinada de contratos, cada uno de los cuales responde a una
Siguiendo estos lineamientos se causa autònoma, aun cuando en conjunto tiendan a la realizaciòn de una operaciòn econòmica unitaria y compleja"6. Hay un negocio ùnico que se desmembra en distintos contratos, como ocurre en la venta de equipos de computaciòn: hay un contrato sobre el hardware, otro sobre el software, otro de asistencia. De este modo, se prescinde de un enfoque voluntarista, que encuentra el nexo en la voluntad de los contratantes, para pasar a un abordaje objetivo, basado en la nociòn de causa ; la conexiòn objetiva es dada por el negocio al que sirven los contratos.

Esta conexiòn entre contratos puede darse unilateralmente (contrato accesorio de un principal), recìprocamente (contratos dependientes entre sì por una operaciòn econòmica).

Siguiendo con la tesis de Galgagno, se indica que la relevancia principal de este instituto es que, si bien los contratos mantienen su individualidad, los efectos de uno (invalidez, resoluciòn) pueden repercutir sobre el otro.

En Francia tambièn se ha tratado el tema bajo el nombre de "grupos de contratos". Larroumet ${ }^{?}$ por ejemplo, analiza el efecto relativo de los contratos y el principio de inoponibilidad, y a partir de ello examina algunos casos que constituyen excepciòn a esas reglas. La existencia de contratos coligados puede dar lugar a acciones extracontractuales directas de un tercero damnificado, como ocurre con el caso del consumidor que demanda contra el fabricante, o con el tercero dañado por hechos del subcontratista de obra que de. manda al locatario principal de la obra. Avanza màs en la cuestiòn cuando se ocupa de los grupos de contratos y de las acciones contractuales.

En este sentido dice el autor que el vìnculo econòmico entre dos contratos se debe duplicar en uno jurìdico, y que de una manera general puede estimarse que siempre que el contrato entre $\mathrm{A}$ y $\mathrm{B}$ ha hecho necesaria la celebraciòn de un contrato entre $\mathrm{B}$ y $\mathrm{C}$, el perjuicio sufrido por $\mathrm{C}$ como consecuencia de un incumplimiento de la obligaciòn contraida por $\mathrm{A}$ hacia $\mathrm{B}$, deberà ser reparada. De este modo, $C$ tiene una acciòn contra $\mathrm{B}$ y contra $\mathrm{A}$. La tesis màs avanzada en este sentido sostiene que quien integra un grupo de contratos no es un tercero y por ello puede tener una acciòn contractual.

Llegados a este punto, el autor se detiene a señalar las dificultades que presenta una interpretacion laxa del principio de la relatividad de los contratos y de su inoponibilidad. En tal sentido señala que es dificil establecer lìmites y que no hay una definiciòn del grupo de contratos.

Estas, tesis presentan una aproximaciòn màs clara a la realidad, aunque es necesario desarrollar mejor los instrumentos normativos.

Por esta razòn haremos una presentaciòn del fenòmeno teniendo en
6. GALGAGNO, Francesco, "El negocio juridico", trad Blasco Gasco-Prats Albentosa, Valencia, 1992, Tirant Lo Blanch, pag. 114. 7. LARROUMET, Christian, "Teoria General del Contrato", De. Temis, Bogotà, 1993, vol II pag 193 y ss. 
cuenta no sòlo los efectos frente a terceros, sino tambièn los que tienen las partes entre sì.

\section{III) La teoria sistemica}

La teoria jurìdica que permita explicar y establecer reglas para solucionar los conflictos que presentan las redes, no puede dejar de considerar la novedad que ellas presentan. El enfoque no puede basarse en el contrato, sino en la interacciòn de un grupo de contratos que actùan en forma relacionada, de modo que el contrato es un instrumento para la realizaciòn de negocios.

Este enfoque, permite establecer que hay una finalidad negocial supracontractual que justifica el nacimiento y funcionamiento de una red. El grupo que surge de esa manera, no es sòlo una uniòn convencional de contratos, que puede ser analizada mediante el examen de los vinculos individuales. Se requiere una comprensiòn del sistema y por ello, de una teorìa sistematica.

Nuestro propòsito es desarrollar este enfoque, pero, a fin de proporcionar una guia de nuestra labor, presentaremos un resùmen de las proposiciones.

Las redes contractuales deben ser captadas en dos planos, referidos a sus aspectos internos y externos.

\section{Relaciones entre las partes: elementos y deberes \\ sistematicos}

En las relaciones internas, las redes presentan un nexo que està vinculado a la colaboraciòn entre las partes que la integran. El elemento unificador es la conexidad, que debemos diferenciar claramente de la integraciòn total o parcial, de naturaleza societaria. La referida conexidad es un componente que fundamenta la existencia de elementos propios de la red como la causa sistematica, la finalidad supracontractual y la reciprocidad sistematica de las obligaciones. Asimismo, da origen a obligaciones sistematicas, de modo que las partes tienen entre sì obligaciones principales, accesorias y deberes secundarios de conducta, y ademàs, deberes referidos al sistema que integran.

\section{Relaciones frente a terceros}

\section{A) Acciones directas} extracontractuales y contractuales

En las relaciones externas, la red se vincula con los consumidores. Estos se relacionan con un integrante de la red, planteàndose la cuestiòn de si le asisten acciones respecto de otros miembros. Surge aquì el obstàculo del efecto relativo de los contratos conforme al artìculo $1195 \mathrm{del}$ Còdigo Civil que impide, como regla general, este tipo de acciones.

Establecida la regla, corresponde ver las excepciones. En este sentido encontramos hipòtesis de acciones directas extracontractuales y contractuales.

? Extracontractual: Para los terceros, el contrato celebrado por los integrantes de la red es un hecho jurìdico, razòn que obstaculiza la existencia de acciones directas fundadas en el contrato. Se han encontrado distintas hipòtesis para fundar acciones:
? responsabilidad por el hecho de dependientes: a travès de una interpreta ciòn amplia de la garantìa por el hecho de dependientes, se puede encontrar una "autorizacion" de un integrante de la red hacia otro. Es el caso del fabricante que autoriza a un servicio ùnico para sus productos, que veremos màs adelante.

? responsabilidad por control: una clase de control especifico, sobre la prestaciòn, puede provocar responsabilidad. Es el caso de las obras sociales que veremos.

? responsabilidad por la apariencia la apariencia jurìdica creada, puede dar lugar a acciones contra el titular de la marca de un producto elaborado ${ }^{8}$.

? responsabilidad por riesgo: en el caso que uno de los integrantes utilice $\mathrm{co}$ sas riesgosas de propiedad de otro.

? Contractual: en algunos supuestos se han admitido acciones contractuales directas:

? existencia de un vìnculo asociativo entre las partes que permite fundar una imputaciòn. Es el caso del Shopping cuando constituye una empresa comùn con los locatarios.

? contrato a favor de terceros: en virtud del articulo 504 del Codigo Civil se han otorgado acciones directas al beneficiario de una estipulaciòn ajena. Es el caso del paciente en el contrato medicosanatorio.
? estructura del vinculo obligatorio: en similares casos que el anterior, es decir en la responsabilidad de las clinicas, se ha utilizado esta argumentacion para dar acciones directas al paciente.

\section{B) Acciones indirectas}

Aunque su utilidad es relativa, existe la posibilidad de la acciòn subrogatoria fundada en el artìculo 1196 del Còdigo Civil.

Nuestra tarea tratarà de avanzar en el descubrimiento de los conceptos adecuados para explicar normativamente a las redes contractuales y desentrañar los efectos jurìdicos que de su funcionamiento se derivan.

\section{SEGUNDA PARTE:}

\section{Relaciones internas}

\section{I) Elementos tipificantes y Caracteres:}

\section{Colaboraciòn gestoria:}

En la colaboraciòn gestoria, una persona se vale de otra para realizar algunas tareas que no puede hacer por sì misma, producièndose una descentralizacion de ejecuciones. Lo que antes ejecutaba el titular por sus propios medios, ahora lo hace a travès de otro.

Entramos asì en la "ratio" jurìdica del mandato: este es un encargo, un "iussum", una interposicion gestoria o representacion

En el derecho argentino, no existiendo una ley que autorice a responsabilizar al titular de la marca puede fundarse en la apariencia. Conf. ALTERINI, Atilio, "Responsabilidad por la apariencia". Derecho de Daños, La Rocca, Bs.As. 
indirecta ${ }^{9}$. Como bien dice Diez Picazo, la representación aparece como una respuesta del orden jurídico al problema social típico de la gestión y cuidado de los bienes e intereses ajenos ${ }^{10}$.

El interès en el negocio no se comparte, y por ello es un vìnculo sin finalidad comùn; sòlo se delega la ejecuciòn. En cambio, en la colaboraciòn asociativa, se comparte el interès, asociàndose las partes en su consecuciòn.

La fuente de esta colaboraciòn puede ser anterior al negocio mediante la simple autorizaciòn o el mandato, o posterior, como ocurre con la ratificaciòn, que equivale al mandato. Puede ser hecha conocer al tercero o no, distinguièndose entonces entre el mandato oculto y el que no lo es.

En todos los casos, la imputaciòn llega hasta el titular del interes. Cuando hay representaciòn, es directa; cuando hay mandato no representativo, es indirecta; cuando hay gestiòn, se produce a travès de la ratificaciòn posterior.

De modo tal que es la sede del interès la que determina la imputaciòn. El dueño del negocio, al que se le permite actuar por otros, tambièn responde por ellos, con intensidad diversa. Cuando ese otro es un dependiente, responde por el hecho del auxiliar; cuando es un colaborador vinculado por un contrato de colaboraciòn gestoria, responde en tanto titular del interès y conforme a los mecanismos expuestos.
Este tipo de colaboraciòn tiene una larga historia. En el derecho romano se lo utilizò para satisfacer las necesidades del pater familias de atender la taberna o la navegación por otro. En nuestros tiempos, se utiliza sobre la base del mandato, para explicar toda clase de encargos.

En las fenomenos que estudiamos en este capitulo, no se trata de una sola delegaciòn de un comerciante a otro, sino de muchisimos encargos que crean una red: red de franquiciantes, de distribuidores, de concesionarios.

El problema que presentamos es el siguiente: icomo se explica la utilizacion de una red de franquiciantes, de distribuidomultiplicidad de delegaciones gestorias: ihay algùn efecto específico derivado del hecho de que se trate de una multiplicidad de contratos?.

\section{Colaboracion asociativa:}

A diferencia del supuesto anterior, en estos casos hay una finalidad comùn, ya que se comparte el interès. La colaboraciòn del otro se da en un plano màs intenso, ya que no se trata de un encargo que se da a otro que puede no conocer el interes del titular, sino de lograr juntos un objetivo. La finalidad comùn puede consistir en un resultado a obtener o una utilidad a repar$\operatorname{tir}^{11}$.

Este proposito puede obtenerse mediante una forma organizativa o sin ella. res, de concesionarios?. Hay aquì una

9. TRIMARCHI, Pietro, "zzituzioni di Diritto Privato", 8va ed.Milan, Giuffrè, 1989, pag. 257

10. DIEZ PICAZO, "La representacion en el derecho privado", Civitas, Madrid, 1979, pag. 24

11. Sobre estos temas conf: Richard, Etrain,"Organizacion asociativa", Zavalia, Bs.As. 1994.
Cuando se utiliza una organizacion, esta puede producir como efecto una persona juridica, como en la sociedad, o no, como en la union transitoria de empresas. En la sociedad, los individuos se diluyen detras de la personalidad obtenida, y las ganancias se obtienen a titulo derivado. En los vinculos asociativos, el proposito comun no hace desaparecer a los sujetos contratantes, y las ganancias se adquieren directamente. Esta tesitura, que comparti$\operatorname{mos}^{12}$ tiene el proposito de evitar la imputacion de sociedad a toda contratacion asociativa, que tiene una larga tradicion en nuestro derecho, como asimismo, promover los vinculos asociativos contractuales no societarios.

Este distingo conceptual es adecuado cuando el supuesto de hecho consiste en la actividad de dos o mas personas, con un proposito comun, que utilizan una figura contractual, tipica o atipica, para la realizacion del proposito.

¿Que sucede cuando la colaboracion se realiza a traves de una multiplicidad de contratos, tipicos o atipicos, pero juridicamente autonomos, y sin embargo puestos en red?.

\section{La colaboracion en las redes contractuales:}

Los grupos de contratos de colaboraciòn gestoria comprenden las redes de distribucion como los grupos de franquicia o de concesionarios.

Los grupos de colaboracion asociativa incluyen los hipercentros de consumo, la subcontrataciòn masiva, el industrial armador, los paquetes de negocios. Los grupos de consumidores abarcan tanto los circulos de ahorro para la compra de bienes, los fondos comunes de inversiòn, las jubilaciones contratadas con las administradoras de fondos de pension, los usuarios de tarjetas de creditos, las comunidades reales, los grupos de suscriptores de medicina prepaga.

Cuando hay una multiplicidad de contratos en red significa que, si bien son autònomos, deben convivir, su existencia no se explica sino a partir de la vida en comun. Lo esencial en ellos es que se logra un efecto de conjunto superior a la suma de las individualidades.

\section{Integracion y conexidad:}

Cuando tienen interes en hacer algo en comun, dos individuos pueden unirse y constituir una sociedad, de modo tal que crean una persona juridica distinta a los fines imputativos. Este es un supuesto de integracion total, en el que se dan los siguientes elementos:

- creacion de una persona juridica que absorbe a los sujetos contratantes.

- adquisicion de ganancias a titulo derivado, de modo tal que primero las obtiene la sociedad y luego, por distribucion de las mismas, los socios participantes.

- el interes es una finalidad comun: un proposito, o una obra, o una utilidad a repartir.

12. Hemos ampliado en Lorenzetti, Ricardo, "Los contratos asociativos y el joint venture", LL. 1992-D-789. 
- la satisfaccion de ese interes se logra a traves del contrato de sociedad.

Estos dos individuos pueden prescin dir de la formacion de una persona juridica distinta y asociarse para obtener el interes mediante un contrato asociativo. Las ganancias no pasan por el filtro de la sociedad, sino que se adquieren directamente.

En ambos casos es la causa asociati va la que origina la integraciòn, sea total parcial.

En la conexidad no existe tal supuesto. Los vinculos individuales pueden ser asociativos o de cambio; no existe una causa juridica asociativa inicial que por la via contractual origine la integracion. Hay, en cambio, una causa econòmica que hace que una serie de vinculos individuale deban funcionar como sistema. El elemen to asociativo se adosa a ellos como atmòsfera envolvente.

De tal modo, la conexidad es un presupuesto del funcionamiento del siste ma de relaciones juridicas interdependientes. A diferencia de la integraciòn, no provoca un vinculo estrecho, asfixiante.

Los vìnculos permanencen individuales pero, por efecto de la conexidad, se unifican para ciertos fines.

El interes, en la conexidad no es intracontractual, sino supracontractual. Se situa mas alla del contrato, en el plano del negocio. Los contratos son un instrumento para la realizacion del negocio global o del sistema ideado.

Por ello podemos distinguir:
- En la integracion hay un interes asociativo que se satisface a traves de un contrato de integracion total o parcial (sociedad, Union transitoria de empresas, agrupaciones de colaboracion empresarias, equipos, ect).

- En la conexidad, hay un interes asociativo que se satisface a traves de un negocio que requiere de varios contratos unidos en un sistema.

- La causa asociativa contractual vin cula a sujetos en tanto son partes de un mismo contrato con una tipologia determinada.

- La causa asociativa negocial o conexidad, vincula sujetos que son parte de distintos contratos, que pueden tener o no el mismo tipo. Por ejemplo, en el sistema de tarjetas de creditos, todos los usuarios son contratantes con el emisor, existiendo muchos contratos de un mismo tipo. En cambio, en la subcontratacion masiva, puede haber un empresario que celebre contratos de limpieza, de suministro, de locacion de servicios, de obra, de publicidad, de modo tal que hay varios contratantes y distintos tipos contractuales.

- En la integracion, la causa asocia tiva es elemento esencial del contrato, lo que tiene trascendencia normativa a la hora de su calificacion e interpretacion.

- En la conexidad, el elemento asociativo se situa en el plano del negocio 0 sistema, y no del contrato. No es entonces un elemento esencial del contrato sino un presupuesto para el funcionamiento del sis tema.
- De tal modo, la conexidad mantiene unidos a los contratos, pero estos conservan su autonomia ${ }^{13}$.

- Lo importante en Derecho, es establecer que la conexidad, aunqu muchas veces es inasible, se solidifica, es base para establecer obligaciones concre tas, entre los integrantes del sistema y hacia terceros.

\section{II) Contrato y sistema}

\section{El interes asociativo en la conexidad contractual}

En la conexidad hay un intere asociativo que se satisface a traves de un negocio que requiere varios contratos unidos en sistema; la causa en estos supuestos vincula a sujetos que son partes de distintos contratos situandose fuera del vinculo bilateral pero dentro del sistema o red contractual. Ello significa que hay una finalidad economico-social que trasciende la individualidad de cada contrato y que constituye la razon de ser de su union; si se desequilibra la misma se afecta todo el sistema y no un solo contrato ${ }^{14}$.

Investigando este aspecto, debemos definir cual es el interes que mantiene unida a las partes en contratos conexos, y luego, que reglas pueden deducirse del mismo. En especial desarrollaremos la idea de que existe un principio de coordinacion, correspectividad sistematica de las prestaciones, y obligaciones con fundamento en la conexidad. Estas ultimas vinculan a los integrantes de la red entre si y frente a terceros. Entre las obligaciones internas cabe mencionar: la de contribuir al sostenimiento del grupo y, la de aseguramiento del exito de la empresa.

Estos elementos sirven para explicar las obligaciones reciprocas que tienen los integrantes de una red de concesionarios, franquiciantes, usuarios de tarjetas de credito y otros sistemas similares.

\section{A) El interes como elemento de la conexidad:}

La nociòn de "interès", ha sido enfocada de modos diversos. Cuando se lo identifica con el dominio, es la relacion de disfrute con la cosa, y el titular del interes es el propietario.

Utilizando esta base, se lo ha aplicado analògicamente al mandato, de modo que tal que el mandante es una suerte de "dominus", que delega en otro la ejecuciòn. El titular del interés es aquel sobre cuyo patrimonio repercuten los efectos del acto para cuya obtención se procura la colaboración de otro. El interés es una guia

13. Frente al fenòmeno de que los planetas del universo tienen existencia autònoma, pero tienen una configuraciòn de sistema, los astronomos se se han formulado la siguiente pregunta: ¿que es lo que los mantiene unidos?. Esto dio lugar a que, desde tiempos inmemoriales, se afirmara la existencia del eter, que es un fluido inasible, que llena el espacio, y constituye un medio continuo con aptitud para transmitir todos los movimientos. Los iusprivatistas pueden preguntarse: ique es lo que mantiene unidos a los contratos en red?. La conexidad es un elemento similar al eter; es una sustancia inasible, invisible, pero que aunque no la veamos, "deberia" existir, porque de lo contrario no se explican los movimientos coordinados.

14. es lo que pasa con un sistema de tarjeta de creditos en el que sus miembros no pagan, o de medicina prepaga, en el que se produce la necesidad de pagar una prestacion exhorbitantemente costosa; sobre este concepto ver ntro comentario en "Las normas fundamentales de Derecho Privado", cil. 
para quien cumple el encargo. La desviación del mandato es legitima cuando es de un modo más ventajoso para el titular del interès (art. 1906 CCArg).

En los supuestos de conexidad que examinamos, tambièn existe la nociòn de interès, pero con algunas particularidades.

- El interès es el centro de union, es el "cemento" que une a los distintos contratos.

- No se trata del interès de un titular individual, sino del grupo o agrupamiento, es el interès en el funcionamiento del sistema.

De ello se deducen dos principios importantes.

\section{B) El principio democratico- conexidad y dominacion:}

Para identificar el interes del titular del dominio o del dueno de negocio en mandato, se recurre a la voluntad declarada por este. Cuando hablamos de interes sistematico, la nocion pierde su carga subjetiva, y aunque el sistema pueda haber nacido de la voluntad de alguien, se independiza y funciona objetivamente.

De tal manera que, para interpretarlo, hay que recurrir al interes del sistema y no del sujeto que le dio origen. Como se trata de un agrupamiento de individuos y una colectividad de contratos, en los que es necesario establecer una convivencia, es

15. Por ejemplo: la clàusula que condiciona la locacion de un local en un shopping de Capital Federal, a instalarse tambien en una sucursal del interior; o la que impide contratar en otro shopping de la competencia. Las que pactan el precio en un porcentaje de las ventas, pueden desnaturalizarse cuando ese porcentaje es demasiado alto y acompañado de auditoria de ventas que importan una injerencia abusiva. En otros casos, existen clàusulas que obligan al locatario a soportar el costo de alquileres por locales vacios, durante un tiempo que se acuerda.

Revista da Faculdade de Direito da UFRGS, v. 16, 1999 necesario recurrir a la regla de la

Recurrimos aqui a la comunicabilidad de los principios de derecho publico y privado para señalar que los principios de la organizacion de la competencia son aplicables para estos casos.

Es claro que pueden existir grados de conexidad; pueden existir clàusulas que la acentùen, poniendo en duda si se està ante relaciones conexas o una dependencia màs acentuada ${ }^{15}$. Hay una zona gris: la conexidad puede transformarse en dominacion, en integracion vertical, en la que desaparece la autonomia negocial, la ajenidad de riesgos.

Naturalmente, la linea de separaciòn depende de cuestiones de hecho que deben ser definidas judicialmente.

\section{C) El principio de la coordinacion:}

Como derivacion de la existencia de un interès para el cual colabora un grupo de contratantes, surge otro principio que, es el de la coordinacion.

Quien concurre a una clinica y recibe una oferta para ser intervenido quirurgicamente, supone que el cirujano actua coordinadamente con el anestesista, con la enfermera y la instrumentista, con el bioquimico y el radiologo. Aunque no se lo pacte de esa manera, ello esta implicito, convivencia democratica. puesto que no es posible pensar que alguien se someta a la actuacion de un grupo de individuos que actua alocadamente y sin un orden interno.

Quien integra una red de distribucion, supone lo mismo, de modo tal que ningun integrante de la red interferira en su zona, o quien la constituyo no tomara medidas que conduzcan al exterminio de la red. La jurisprudencia ha tenido ocasion de poner de relieve este aspecto con frecuencia: por ejemplo, con relaciòn a los contratos de concesion se ha señalado que se està ante un contrato normativo de coordinacion ${ }^{16}$.

El principio de la coordinacion que se deriva de la existencia conexa de contratos en torno a un interes sistematico, causa la existencia de obligaciones. No se trata de contratos de coordinacion, sino de obligaciones $o$, deberes secundarios de conducta, que se adosan a contratos que conviven entre si de modo sistematico.

Ello significa que todos los integrantes de una red contractual, tienen una obligacion de colaborar en el funcionamiento del sistema, obrando de modo tal que su conducta sirva para el mantenimiento del mismo. Aqui, la causa asociativa del negocio grupal se hace presente, se solidifica, para fundar una pretension de colaboracion

Estas obligaciones tambien alcanzan al organizador del sistema, quien no puede

\section{CNCOM, SALA E. ED. 109-614}

"conf. MOSSET ITURRASPE, Jorge, "Contratos", Rubinzal y Culzoni, Santa Fe, 1995, pag 47.

18 Cont: FRIED, Charles, "Contract as Promise. A theory of Contractual Obligation", Harvard Univ Press, 1981

19. conf BUERES, Alberto, "Objeto del negocio juridico", Hammurabi, 1986, pag 111 adoptar conductas o imponer medidas que lleven a la destruccion.

Este es un criterio para determinar el abuso. La regla seria el imperativo categorico kantiano con una pequena modificacion: obra de modo tal que tu maxima de obrar pueda ser elevada a ley "sistematica" del obrar. Asi todos deben obrar de modo tal que no destruyan el sistema.

\section{Equilibrio del contrato y del \\ sistema:}

\section{A) La correspectividad} sistematica de prestaciones:

El contrato ha sido identificado por la doctrina argentina con el negocio juridico bilateral ${ }^{17}$ En este aspecto en el derecho anglosajon ocurre algo similar al considerar al contrato como promesas a las que la ley les otorga fuerza legal, pero siempre dentro de un vinculo bilateral ${ }^{18}$. De alli que tanto la doctrina de la "causa objetiva", la del "objeto como operacion juridica considerada por las partes" como la de "consideration", si bien tienen aspectos diferentes, asumen la necesidad de una correspectividad bilateral de las prestaciones.

Lo que debemos aislar es el componente relativo a la correspectividad objetiva de las prestaciones que se mantiene como elemento genetico y funcional en el contrato ${ }^{19}$.

Este aspecto tiene una fundamental importancia en los contratos discrecionales

Revista da Faculdade de Direito da UFRGS, v. 16, 1999 
para juzgar el equilibrio, la reciprocidad, la commutatividad entre lo que da y entrega cada parte en el momento de celebrar el contrato y a lo largo de su desarrollo, y fun damenta la excepcion de incumplimiento contractual, el pacto comisorio y la excesiva onerosidad sobreviniente 20 . En la contratacion de consumo, la clausula es abusiva cuando "desnaturaliza" las obliga ciones o cuando importen renuncia o restriccion de los derechos del consumidor o ampliacion de los derechos de la otra par te (art. 37 ley 24240), lo cual significa que el vinculo debe tener reciprocidad ${ }^{21}$. Mas clara aun en este aspecto es la ley francesa 95-96 de febrero de 1995 , relativa clausulas abusivas, que las califica como aquellas que "tienen por objetivo o po efecto crear, en detrimento de la parte no profesional o consumidor, un desequilibrio significativo entre los derechos y las obligaciones de las partes del contrato".

La idea de equilibrio y correspectividad se ha ido expandiendo.

Durante mucho tiempo se la entendio en el plano obligacional, como "obligacio nes reciprocas", porque la prestacion de una tiene razon de ser en la prestacion de la otra (art. 1139 CC), dando fundamento a un sis tema de vasos comunicantes entre obligaciones. Asi, si el comprador de un inmueble no puede exigir la escrituracion si no pago el precio, porque hay correspectividad entre ambas obligaciones ${ }^{22}$.

\section{0. conf BUERES, op cit.}

21. ampliamos esta nocion al tratar las clausulas abusivas en MOSSET ITURRASPE, Jorge, LORENZETTI, Ricardo, "Defensa del Consumidor-Ley 24240", Ed. Rubinzal y Culzoni, Santa Fe, 1994.

22. ALTERINI-AMEAL-LOPEZ CABANA, "Derecho de Obligaciones civiles y comerciales", Abeledo Perrot, Bs.As., 1995, pag.69.

23. conf. entre otros BUERES, Alberto, "El objeto del negocio juridico", Hammurabi, Bs.As.

Revista da Faculdade de Direito da UFRGS, v. 16, 1999
Para entender este tema nos parece de interès comentar un caso fallado por la jurisprudencia argentina ${ }^{24}$. La parte actora habia celebrado un contrato de medicina prepaga. Normalmente transcurre un tiempo inicial de carencia de servicios que es costumbre en la actividad y durante el cual paga pero no recibe nada. Luego del mismo, es habitual que no se requieran grandes gastos al sistema prepago, porque los estudios que se hacen al contratar son bastante rigurosos y es raro que una persona muy enferma sea admitida, si no es a un precio mayor.

Lo cierto es que el solicitante del servicio tiene un tiempo prolongado en el que paga y no recibe servicios. Es el periodo de mayor rentabilidad de la empresa.

Luego de un tiempo, la persona se enferma. La tendencia se invierte, puesto que la empresa debe comenzar a gastar mucho màs dinero del que recibe por la cuota que va pagando el prestatario.

Como puede advertirse claramente, las curvas de la utilidad marginal son inversas como sucede habitualmente en los contratos de duracion.

Se supone que llegado al punto en que debe gastar màs de lo que recibe, la prestadora difunde este costo de dos maneras. En primer lugar lo compensa con lo que ha recibido antes de parte del prestatario ahora enfermo; tal es la funciòn de los perìodos de carencia.

En segundo lugar, la existencia de una masa de afiliados permite difundir en- tre todos los costos del sistemas, operàndose compensaciones entre los que estan sanos y los que estàn enfermos, que suelen ser menos; de tal modo constituyen una carga econòmica soportable para el resto, si el càlculo actuarial està razonablemente bien realizado.

Volvamos ahora al concepto de causa y a la exigencia de prestaciones recìprocas.

En primer lugar hay que ajustar el concepte en los contratos de duraciòn: la correspectividad debe examinarse durante todo el tiempo del contrato. En el caso que tomamos como base, al principio, cuando el prestatario paga y no recibe prestaciones; al enfermarse, paga poco y recibe muchas prestaciones medicas. Un anàlisis bilateral de cada momento, llevarìa a una conclusiòn de que no hay obligaciones reciprocas; sin embargo, debe evaluarse toda la temporalidad del contrato de duracion. Este es el criterio que sirve para descalificar el argumento de que a la empresa le resulta onerosa la prestaciòn medica tomando en cuenta el pago que realiza en èse momento el consumidor.

En segundo lugar y aùn tomando en cuenta todo el ciclo temporal, habrà que evaluar el sistema. Supongamos que la empresa es obligada a dar atenciòn medica a un enfermo cronico, que requiere atenciòn medica permanente y costosa durante el resto de su vida ùtil, que podrìamos estimar en veinte años como hipòtesis. En este caso, la empresa descargarà los costos en el sistema, es decir en el resto de los contra-

24. JUZG. NAC. COM. n. 11. $1^{\circledR}$ inst. firme, 23/12/93- Heliszkowski, Michel y otros v. Programa de Salud S. A., Jurisprudencia Argentina, $27 / 7 / 94$.

Revista da Faculdade de Direito da UFRGS, v. 16, 1999 
tantes. Podrìamos preguntarnos entonces porquè razòn los integrantes de ese grupo deberìan soportar esa carga y si es justo que asì suceda. En la mayoria de los sistemas jurìdicos, esta carga ha sido considerada excesiva para los grupos contractuales y se la difundido a travès de la seguridad social. De tal modo, podrìa imponerse la obligaciòn a la empresa de modo transitorio, hasta que la seguridad social pueda asumir el costo, y sin que desequilibre el sistema contractual.

Esta obligaciòn, sin las precisiones antedichas, si bien satisface el derecho a la salud, desequilibra el sistema.

Por ello entendemos que hay que hablar de una "correspectividad bilateral" y de una "correspectividad sistematica de las prestaciones". Esta ùltima deberìa ser entendida como la reciprocidad existente entre lo que cada uno de los integrantes del sistema paga y lo que sistema puede satisfacer de acuerdo con su racionalidad economica.

\section{B) Deberes colaterales sistematicos}

Un sistema es un conjunto de partes interdepedientes de modo tal que una de ellas no puede existir plenamente sin el con curso de las otras. Cuando hay un "sistema de contratos" ocurre exactamente lo mismo, de modo que hay un problema de convivencia ${ }^{25}$; son contratos distintos, pero no pueden convivir uno sin el otro; no funciona ninguno si el sistema fracasa.

Asi sucede en el sistema asegurativo, porque si se generaliza la falta de pago, o

25. C1RA CIV Y COM BAHIA BLANCA, SALA 1RA, LL.7.8.92. todos los asegurados mienten al contratar ocultando enfermedades preexistentes, o todos sobreutilizan las prestaciones, se produce un descalabro.

El incumplimiento de las obligaciones contractuales nó se agota en sus efectos bilaterales, sino que es perceptible una repercusion en el sistema.

Esta circunstancia da lugar a una serie de conceptos que, desde nuestro punto de vista deben comenzar a desarrollarse en una economia caracterizada por prestaciones masivas y vinculadas a traves de redes:

- La finalidad supracontractual, que se refiere a los objetivos buscados y solo obtenidos a traves de una red de vinculos. En cambio la finalidad economico-social en el sentido de causa objetiva, se refiere a lo que se busca mediante el contrato.

- La existencia de deberes secundarios de conducta, respecto del funcionamiento del sistema. De alli el principio de coordinacion que genera un deber de cada una de las partes a contribuir en el sostenimiento del todo.

Las partes tienen deberes secundarios de conducta respecto del sostenimiento del mismo. El "sistema" no se identifica con la empresa que lo organi$z a$, de manera que siempre se deba interpretar en favor del mantenimiento de la empresa.

Las uniones de contratos de este tipo, requieren de una interrelacion economica y tecnica que debe ser mantenida para su funcionamiento, conformandose el equilibrio objetivo que denominamos causa sistematica. Es incompatible con el mismo que se impute a la empresa cargas excesivas, que luego volcara sobre los demas contratantes integrantes de la red, como tambien lo es que la empresa establezca clausulas abusivas que desequilibren el sistema haciendo que solo los consumidores soporten los riesgos.

Los deberes secundarios corresponden a todas las partes y la causa sistematica es el elemento moralizador.

\section{C) Afectacion de la causa derivada de la traslacion de riesgos a los consumidores}

La empresa puede buscar trasladar los riesgos a los consumidores mediante una serie de clausulas que provocan ese efecto. De alli la rescision unilateral incausada, la limitacion de responsabilidad, la modificacion unilateral de precios, y otras que la jurisprudencia ha descalificado.

Veamos como se produce ese efecto. En el caso ya comentado sobre rescision unilateral incausada enla medicina prepaga se supone que la existencia de una masa de afiliados permite "derramar" sobre ellos los costos de atencion, operàndose compensaciones entre los que estan sanos y los que estàn enfermos. Normalmente la estadìstica muestra que sòlo una pequeña parte estàn enfermos, y que no es habitual que todos enfermen al mismo tiempo. Excepciòn de ello son algunos sistemas que nuclean a personas de edad avanzada y generalmente enfermas, como el Instituto de Servicios Sociales para Jubilados y Pensionados (Pami), pero por esa misma razòn, la difusiòn del riesgo se amplia cargando con contribuciones directas a quienes no son jubilados ni pensionados, esto es, al personal activo. La empresa percibe una masa de dinero aportada por un grupo, y solo una parte de ellos gasta, de modo que si se mantiene este equilibrio, puede pagarle a los enfermos, soportar sus gastos y obtener una ganancia. El calculo probabilistico es el que posibilita este funcionamiento.

El-riesgo de la empresa reside en hacer bien o mal ese calculo, en administrar mejor o peor, en el modo de seleccion de su cartera, en la diversificacion de riesgos. La empresa puede disminuir esos riesgos o aumentarlos, segun sea mas o menos seria, mas o menos eficiente; lo que no puede hacer es trasladarlos.

Si la empresa no disminuye sus riesgos, sino que los traslada a los consumidores, afectara el equilibrio sistematico. Por ejemplo:

- si mantiene el contrato mientras el paciente paga y no gasta, pero lo rescinde cuando el paciente se enferma, se rompe el equilibrio. Su deber es absorber estos gastos con las previsiones y con compensaciones con los otros adherentes.

- cuando con el transcurso de los anos el paciente comienza a gastar mas, la empresa no puede modificarle las condiciones. Puede solucionar el problema contratando nuevos adherentes jovenes que establezcan las compensaciones necesarias dentro del sistema.

Si frente a estas situaciones previsibles no puede reaccionar, es porque hizo mal 
sus calculos y debe afrontar ese riesgo empresario.

La empresa no puede obrar de modo que contradiga esta circularidad de efectos basados en el calculo probabilistico.

Veamos ahora una situacion contraria.

\section{D) Afectacion de la causa} derivada de la imposicion de cargas publicas a la empresa

La imposicion de una carga publica en un contrato o en un sistema contractual puede ocasionar un desequilibrio.

Ello es particuparmente claro en los sistemas de base asegurativa. Si por ejemplo, en la medicina prepaga, se establece que un enfermo cronico debe ser atendido sin limites, o en el seguro, se anulan todas las clausulas que delimitan el riesgo, o se le imponen deberes que no pueden ser soportados por la masa de individuos asegurados, se producen distorsiones.

La empresa puede delimitar los riesgos que asegura. De hecho si cubriera todos los riesgos de una persona durante toda su vida estaria obrando de mala fe; ya que este debe ser individualizado para que sea posible establecer un seguro, y ello se hace mediante limites temporales y materiales. El contrato establece que es lo que se cubre y lo que se excluye, lo cual es esencial para el funcionamiento del seguro.

De alli que la exclusion de cobertura sea un supuesto de limitacion del riesgo, es decir del objeto del contrato y sea licita, y

26. STIGLITZ, Ruben "Derecho de seguros", cit, pag 172 no sea admisible la interpretacion analogica ni extensiva ${ }^{26}$. En cambio, si una vez delimitado el objeto, esto es el riesgo asegurado, la empresa lo desnaturaliza mediante disposiciones que lo trasladan al consumidor, hay una clausula abusiva.

En virtud de esta diferenciacion, hay una delimitacion del riesgo que es licita, porque la empresa no asume todos los riesgos. Si estos existen, y el individuo no puede soportarlos individualmente, y hay una garantia minima como derecho fundamental, debe ser una carga publica del Estado.

Si estas cargas publicas que exceden el riesgo asegurado se imponen a la empresa; si estos desequilibrios son superiores al calculo probabilistico, se produce una crisis del sistema y en el ambito juridico, una afectacion de la causa sistematica.

Puede ocurrir que el Juez decida imponer garantìas transitorias a los contratantes, aun violando la voluntad de uno de ellos o rectificando lo pactado. Ello se justifica por razones de urgencia y por la ausencia de alternativas de satisfaccion de la garantia. En cambio, si hay alternativas para el ejercicio de esta garantìa minima del derecho fundamental, no hay porquè imponerlas al contratante.

\section{III) El control a traves de la red}

\section{Estructura interna de la red}

Una de las cuestiones que plantean las redes contractuales es el problema de las relaciones internas. No se trata del problema de los derechos y deberes de las partes, sino de la conformacion del sistema de contratos.

La red puede presentar una estructura autocratica, que se caracteriza porque existe una empresa central, que planifica la conducta de todos los demas y la controla de modo similar a la dependencia. Estas ultimas estan destinadas al desuso en una economia competitiva, en las que se requiere una alta participacion en las decisiones de todos los integrantes, una fluida comunicacion y un proceso de interaccion creativo, que no pueden brindar las organizaciones de este tipo.

Las formas democraticas, se caracterizan por presentar una descentralizacion mayor en las decisiones. En el plano juridico ello significa que se trata de vinculos entre empresas autonomas, que asumen el riesgo empresario.

Sobre esta base surgen dos cuestiones relevantes:

La primera es que la empresa organizadora, el ceder el uso de bienes a terceros (marca, imagen, etc) pretende tener un control sobre la conducta de quien los usa, a fin de evitar un deterioro de los mismos. La segunda, es que ese control tiende a transformarse en dominacion, pasando los limites de una configuracion democratica a una autocratica.

El equilibrio entre democracia interna y proteccion de los bienes del organizador

27. Champaud, "Los métodos de agrupación de sociedades", en "Revista de Derecho Comercial y de las Obligaciones", p. 18, añoll, Buenos Aires, 1969

28. Conf Morandi en un voto publicado en LA LEY-1983-C. 240 . y la frontera entre control y dominacion son cuestiones que de dificil solucion, que esbozaremos seguidamente.

\section{Concentracion vertical y}

\section{horizontal de empresas}

Uno de aspectos investigados sobre la configuracion interna de las redes contractuales es el relativo a la concentracion vertical $u$ horizontal de empresas ${ }^{27}$. Este tema es enfocado desde el derecho de la competencia, en tanto estos vinculos superen un nivel de integracion que permita hablar de acuerdos colusorios violatorios de la libre competencia en el mercado; desde el derecho societario, dentro de la teoria de los agrupamientos; en el derecho concursal, para la extension dela quiebra. Desde el punto de vista juridico, enfocando la cuestion exclusivamente en el aspecto contractual, y en lo que resulta relevante para el tema de las redes, trataremos dos facetas: la primera relacionada el agrupamiento piramidal u horizontal, y la segunda con los instrumentos contractuales para lograrlo.

La concentracion vertical supone una configuracion piramidal de la red, puesto que hay una empresa que esta en la cuspide y que controla a las demas. El caso mas tratado en doctrina y jurisprudencia es el de las concesiones de automotores, en el que hay un fabricante-proveedor y una multiplicidad de concesionarios que se ubican en un escalon inferior, de subordinacion economica. En los aspectos juridicos se ha dicho ${ }^{28}$ que "el contrato de concesión para la venta de automotores... tiene las

Revista da Faculdade de Direito da UFRGS, v. 16, 1999 
peculiaridades de un negocio jurídico de "concentración vertical de empresas" ... a través del cual, la concedente incorpora dentro de su estructura funcional dedicada a la distribución de sus productos, a una concesionaria, la que si bien mantiene,.....su independencia jurídica y patrimonial.....se somete a las reglas impuestas por la concedente...", lo que produce "una notoria "desigualdad" de tratamiento, en una vinculación "atípica" ". De esta forma el contrato de concesión, para aquilatarlo en toda su significación y consecuencias jurídicas, debe ser analizado con un "sentido funcional", es decir, sin perder de vista que es el componente de un conjunto de otros contratos idénticos celebrados por el fabricante, para facilitar la existencia de nuevas bocas de expendio de sus productos para el mercado, formando parte de una red de la distribución integrada, y sometida a su dirección y poder ; lo que se expresa, en una "subordinación económica" de las em. presas agrupadas, que subsiste, aun cuando se advierta la autonomía patrimonial y jurídica a que antes hemos hecho referencia".

Esta caracterizacion produce una presuncion de la existencia de dominacion, de lo que se hace derivar una serie de consecuencias protectorias de la parte debil. Desde nuestro punto de vista, no es exactamente el hecho economico de la dominacion, de por si inasible, sino la existencia de instrumentos de control objetables, lo que produce la aplicacion de normas de proteccion.

En la concentracion horizontal, no hay un centro desde el cual parten las directivas, por lo que no hay una configuracion piramidal. Todos los integrantes de la red estan en paridad de situaciones, y actuan conjuntamente, interactuando entre si. En la realidad es dificil que no exista alquien que establezca su predominio, como - ocurre con las estructuras de franquicia, en las que el titular de la marca, lo impone.

El problema se traslada, tambien en este caso, a los instrumentos de control.

No es nuestro proposito desarrollar la teoria acerca del control interno y externo en materia de sociedades y de vinculos contractuales, sino solo poner de manifiesto algunas clausulas que tienen un efecto preciso en la caracterizacion de los contratos.

\section{Tecnicas de control}

Podemos discernir diversos tipos de control, que son tratados habitualmente por distintas especialidades:

- Control societario interno: El contro puede ser logrado mediante participaciones societarias de una empresa en la otra, siendo este un tema propio del derecho societario.

- Control contractual externo: Puede ser obtenido mediante un "entorno" contractual: prestamos financieros, asistencia tecnica, management, cesion del uso de la marca y otros vinculos que dejan libre a la sociedad controlada en su aspecto interno, pero limitan fuertemente su campo de actuacion. En este control, externo, la sociedad ha delegado gran parte de sus actividades que es realizada por otro sujeto, o por varios que pertenecen a una sociedad controlante.

- Control de la prestacion: en este caso un contratante contrata con otro una determinada prestacion, y la controla de manera tal que limita su margen de autodeterminacion.

Este ultimo es el que motivara nuestro analisis. El interes es definirlo claramente y delimitarlo respecto del control de la prestacion que da lugar a la relacion de dependencia laboral.

La importancia de este distingo es enorme, puesto que una gran parte de los contratos que se integran en redes estan sujetos a este control de la prestacion y muchas veces se utiliza la nocion de "dependencia" para subsumirlos en un regimen laboral o bien en la responsabilidad extracontractual por el hecho del dependiente.

\section{El control de la prestacion en \\ el campo laboral y comercial}

El control de la prestacion en el cam po laboral es uno de los aspectos de la subordinacion juridica, y debemos diferenciarlo del control existente en los vinculos de colaboracion autonomos.

En muchos contratos hay control de la prestacion: cuando se contrata a un locador de obra hay un control y supervision muy estricto (por ejemplo en la construccion de una casa), pero no hay dependencia laboral. En un contrato de franquicia, hay un control muy fuerte a traves del manual de operaciones, que guia al detalle la prestacion del tomador de la franquicia, al punto tal que hace desaparecer toda diferencia entre el dador y el tomador $^{29}$. Tampoco hay relacion laboral.
La dependencia laboral se caracteriza por ser algo mas que una que una simple "injerencia", o "control", ya que no se limita al objeto del encargo. Alcanza al "elemento personal", al obrero, quien está jurídicamente subordinado. El obrero se pone a disposicion de los requerimientos del empleador. El poder de dirección afecta aquellos aspectos estructurales: el patrón puede diseñar el modo de prestación con referencia a los horarios, lugar, medios técnicos a utilizar, ordenar la demanda en el sentido de fijar su ritmo.

Es decir, no se limita a un control de la prestacion, sino de la persona.

La violación de las órdenes que da el empleador es un incumplimiento contractual, que puede dar lugar a penalidades como la suspension disciplinaria, cuando está prevista legalmente (art. 67 ley 20744).

Este es un dato revelador de la subordinacion juridica.

No puede confundirse la relacion laboral con los vinculos de colaboracion. En la colaboración hay una finalidad común, un contrato con un tercero que uno no puede hacer sólo y entonces delega en otro. Consecuentemente hay una función de cooperacion de las partes para alcanzar el fin que ha determinado el advenimiento del vinculo. Existe un objetivo que gravita de tal manera que sobredetermina a las partes, haciendo que ellas realicen a través del medio contractual las aportaciones pertinentes para su logro. Ese fin puede consistir en una gestión a realizar (mandato, locacion de servicios), en un resultado a 
obtener (locacion de obra) o en una utilidad a conseguir y dividir (sociedad).

En virtud de la titularidad del interés, a una de las partes se le le concede el derecho de señalar cómo debe desarrollarse el encargo: el mandatario debe ajustarse a las instrucciones (art. 1904 CC), el locador de obra debe ajustarse a las instrucciones del dueño (art. 1632 CC). Por ello, en los negocios de colaboración autónomos, hay una intromisión del titular del interes sobre la actividad de quien realiza la colaboracion y está destinada a precisar el objeto del encargo. trabajo.

Esto es distinto en el contrato de

Al contrario de la regla general, no es el colaborador quien está en relación con el tercero. Es el titular del interés (patron) quien se vincula con otros, y de ahí que el obrero colabora de un modo "instrumen tal". Por eso la dependencia es más fuerte que la injerencia. El contrato de trabajo es un negocio de colaboración dependiente.

De manera que puede decirse que en muchos contratos hay control de una de las partes sobre la prestacion de la otra. En aquellos vinculos en que se alcanza la conducta de la persona fisica involucrada de modo que tiene un caracter instrumen-

tal respecto de la prestacion principal que compromete el empleador, es laboral.

En los casos en que el control forma parte de un vinculo de colaboracion, en los que el titular del interes delega en otro la relacion con los terceros y no la presta el mismo, no es laboral.

\section{El control en los vinculos de colaboracion autonoma: \\ finalidades}

Hay casos en los que el control es dado para proteger un bien de uno de los contratantes cedido en uso al otro, como el know how, la marca $a^{30}$, y otros, y no se deriva del mismo ningun desnivel con relevancia juridica en la proteccion de la parte debil.

Otros controles permiten una intervencion muy fuerte de uno de los contratantes no solo en la prestacion, sino en toda la actividad del otro, como son los que autorizan a quien presta dinero, con facultades de hacer auditoria, imponer deberes de comportamiento empresario, objetivos alcanzar y muchas otras conductas que obedecen a asegurar el riesgo economico y no a proteger la parte debil ${ }^{31}$.

En muchos supuestos el control es un medio de reduccion de costos. Por

30. Conf. FERNANDEZ NOVOA, "Fundamentos de Derechos de Marcas", Madrid, Motecorvo, 1984, pag. 377. Dice el autor que el control es tipico en el derecho de marcas, que puede ser pasivo, o bien incluso activo, como ocurre en la franquicia, donde el tranchisor ejercita un control activo sobre la explotacion empresarial", necesario para la proteccion de su imagen

31. Este es un fenomeno muy comun: desde los paises que, solicitando prestamos internacionales se someten a los controles del Fondo Monetario Internacional, el que a su vez les impone conductas economicas precisas, a las empresas que, para solicitar
prestamos de importancia deben mostrar contabilidades, someterse a auditorias, y muchas veces adoptar conductas especificas prestamos de importancia deben mostrar contabilidades, someterse a auditorias, y muchas veces adoptar conductas especificas impuestas por los Bancos que
estar integrado con el Banco.

Revista da Faculdade de Direito da UFRGS, v. 16, 1999 ejemplo, las obras sociales intervienen en el control de la prestacion de clinicas y medicos estableciendo standards de actuacion, vademecum para la prescripcion de medicamentos, todo con la finalidad de reducir costos que benefician a toda la red.

En otros supuestos, es un elemento caracterizante de la figura. Concretamente en la franquicia, se ha sostenido que el "control significativo" es un elemento del tipo, esencial para que exista el contrato. El mencionado control es "un concepto juridico indeterminado y de concrecion topica, y que implica necesariamente la existencia de una direccion tecnica comercial, e incluso la posible incursion en autenticas funciones de administracion o direccion empresarial en sentido propio, al admitir su extension a aspectos como la politica financiera, de personal o el derecho de establecimiento de la empresa franquiciada" y ello es un elemento decisivo para conseguir un "elevado nivel de integracion e las partes" 32 .

En la concesion tambien hay fuertes controles, aunque menos intensos que en la franquicia porque los elementos en juego en la concesion son tangibles (por ejemplo: automotores, marca) y mas faciles de proteger que el inasible "know how", muy facil de copiar y reproducir. En la concesion suele haber obligaciones de compra, ventas minimas, obligacion de promocion, de no concurrencia, de diseno de los locales, supervision contable, prestamos financieros continuos que ejercen un control muy fuerte sobre el concesionario.

32. ECHEBARRIA SAENZ, Joseba, "El contrato de franquicia", Mac Graw Hill, Madrid, 1995, pag. 28. 33. CNCOM, LL-1983-C-240
El control sirve tambien para aumentar la capacidad de venta de todo el grupo. Por ejemplo, se ha dicho que "la exclusividad impuesta a la concesionaria, afirma en los hechos la superioridad del fabricante durante la vigencia del contrato y, el control, que se establece sobre las conductas y patrimonios de los componentes (que el procedimiento de concentración agrupa), surge como el medio utilizado por la parte directriz para realizar y conservar la "unidad de decisión", incluso para au mentar, en un momento dado, la capacidad de agresión de cada unidad del grupo dentro del mercado (ver Champaud, ob. cit., en Revista, cit., p. 120, apart. 3\%)"33.

\section{Efectos}

La existencia de un control de la prestacion en los vinculos de colaboracion autonoma no activa la presuncion de existencia de una relacion laboral (art. 23 LCT). El efecto en cambio se produce en otros ambitos:

- en el plano del derecho del consumidor, el control puede crear una apariencia juridica frente a terceros que haga responder al controlante frente a los terceros en virtud de la buena fe creencia creada.

- en el plano de la responsabilidad es admisible la regla: a mayor intervencion en la prestacion, mayor responsabilidad.

\section{El ejercicio abusivo del control:}

El control y el ejercicio del poder de direcciòn que del mismo se deriva estàn 
sometidos a limites internos que definen su uso regular. El ejercicio regular del derecho se debe ejercer conforme a finalidades, establecidas por el objetivo que la ley tuvo en miras al reconocer el derecho, la buena fe, la costumbre.

El control y el ejercicio del derecho de direcciòn no escapan a estos lìmites. En materia laboral tenemos un ejemplo, puesto que la ley establece lìmites de este tipo al poder de direcciòn que tiene el empleador sobre la conducta del empleado.

En las redes de contratos el control debe ajustarse a la finalidad que representa el funcionamiento de la red. Por ejemplo, el control que ejerce el concesionario tiene por finalidad el mantenimiento de la red. Por ello puede establecer pautas para preveer que se mantengan stocks, o de servicios a dar a los consumidores o referentes al uso de los signos distintivos. Asimismo, puede definir politicas aracancelarias, financieras, tributarias, comunes para disminuir costos de la red.

El lìmite a estas conductas, està dado por una desviaciòn de la finalidad. Si la causa sistematica es el matenimieto de la red o la disminuciòn de los costos, todas las conductas del concedente pueden examinarse conforme a ese standard.

Si el poder de direcciòn se usa para una finalidad desviada, como por ejemplo para trasladar costos o riesgos a los concesionarios, es un supuesto de uso abusivo.

El control de la red se logra a travès de una serie de clàusulas que son "sospechosas" de abusividad, entre las que cabe mencionar las siguientes:
? Clausula de exclusividad de compra: obliga al franquiciado a adquirir una cantidad de bienes ùnicamente al franchisor, o bien a un proveedor indicado por este.

? Clausula de exclusividad de compra y de venta reciproca: obliga al franchisor a aprovisionarse unicamente del franchisee y a èste a adquirir y distribuir solamente dicha produccion.

? Clàusula de territorialidad simple: otorga al francisee un privilegio de suministros exclusivos en un area determinada, en la que no puede haber ningùn otro negocio similar creado por el dador.

? Clàusula de territorialidad reforzada: al concedèrsele la zona, se obliga al tomador a limitarse a ella, no pudiendo enviar vendedores a otras zonas.

? Clausula de precio uniforme: con el fin de lograr una homogeneidad de todos mìnimo y un màximo, o bien directamente un precio obligatorio a fin de que todos los integrantes vendan al mismo precio.

? Clausula de mantenimiento de stock: obliga al distribuidor a adquirir una cantidad minima y permanente de bienes.

Tambièn es interesante la aplicaciòn del criterio antidiscriminatorio. Entendemos que debe considerarse implìcita una clàusula no discriminatoria: el organizador debe comunicar a todos los integrantes de la red las novedades y no discriminar a algunos miembros. Por ejemplo, si en una red de franquicias sale una nueva tecnologia y no se la prveen a uno de los franquiciados, los integrantes de la red, se establece un ello afectarìa la igualdad y serìa un trato discriminatorio ${ }^{34}$

\section{IV) Efectos entre las partes: deberes de proteccion del sistema}

\section{La obligacion de contribuir al} sostenimiento del grupo:

Con base en la causa asociativa del sistema de contratos, podemos encontrar un deber secundario de conducta consistente en el sostenimiento del grupo.

Ello ha sido declarado jurisprudencialmente en varios casos:

En los planes de ahorro se ha dicho que hay una relacion de "convivencia" entre los contratos, traducida en el comùn interès del buen èxito del mismo, el que està indisolublemente ligado al cumplimiento exacto puntual y riguroso de las obligacio-

En el contrato de concesiòn se ha dicho que debe ser analizado con un "sentido funcional, es decir, sin perder de vista que es el componente de un conjunto de contratos idènticos celebrados por el fabricante para facilitar la existencia de nuevas bocas de expendio de sus productos para el mercado, formando parte de una red de distribuciòn integrada..." ${ }^{36}$.

En los clubes de campo se ha indicado que "es necesario que los condòminos

KLEIDERMARCHER, Jaime "Franchising- aspectos econo 35. CIRA CIV Y COM BAHIA BLANCA, SALA 1RA, LL.7.8.92.

36. CNCOM, Sala B, Cilam c. Ika Reanault

37. CNCIV SALA A., "Mapuche Country Club c. Lopez de Marsetti, Hebe", JA.1989-IV-202.

38. CNESP CIV Y COM SALA II, "Canzone de Traversa, Maria c. Consorcio de Prop. Suipacha", LL.1987.E.92. institucion..."3?. otros" 38 del grupo. hipermercado. nes de cada uno" 35

de los bienes comunes contribuyan al mantenimiento, conservaciòn y mejoramiento de estos ùltimos..." porque la adhesion de cada propietario "se propone dar vida a un resultado jurìdico que es la existencia y continuidad del mismo como

Con referencia al consorcio se ha señalado que para la soluciòn de los conflictos entre propietarios "debe tenerse en cuenta el interès de la comunidad, procurando que la soluciòn no beneficie a algunos propietarios en desmedro de

\section{El aseguramiento del exito de \\ la empresa comùn:}

En algunos casos puede plantearse si existe una obligaciòn de asegurar el èxito

Esta situaciòn puede darse principalmente en supuestos tales como el hipermercado de consumo. La empresa organizadora hace estudios de mercados, planifica un ordenamiento, hace publicidad, y todo lo que ella haga, o deje de hacer, repercutirà directamente en la suerte econòmica de las empresas locatarias del

Es perfectamente posible establecer la frustraciòn del negocio atendiendo a:

- la diferencia entre los estudios realizados, planificaciòn efectuada antes de la 
instalaciòn del shoping y la realidad de ventas y circulacion de poblico en un determinado momento posterior.

- las situaciones en otros emprendimientos similares.

De tal modo, recurriendo a la costumbre del lugar, las exigencias de la naturaleza de la obligacion, el tiempo y otros factores concretos, se puede establecer una aproximaciòn a lo que la empresa debiò hacer y lo que realmente sucedio. La dis. tancia entre un paràmetro y otro nos da una idea de la culpa (art. 512 CC).

Esta omision de diligencias exigibles repercute sobre la economì de cada uno de los locatarios, ya que si hay menos gente en el shoping, habrà menos ventas.

De tal manera podremos encontrar un factor de atribuciòn de responsabilidad subjetivo y un nexo adecuado de causalidad. via:

Sin embargo, hay una pregunta pre

¿Existe una obligaciòn de la empresa organizadora del hipermercado de garantizar que los locatarios tengan un nùmero de publico adecuado $y$ ventas razonables, de modo que su incumplimiento culposo produzca la obligaciòn de indemnizar los daños causados?.

Normalmente la respuesta es negativa porque ello no encuadra dentro de la obligaciones que surgen de la locaciòn de cosas. Si alguien alquila un local comercial en una zona donde circula mucha gente, y luego la gente deja de ir, no hay una

39. CNCiv., sala H, 22/9/94- Carrefour Argentina S.A. c. Kids And Co. S.R.L., LL, 31/5/95 obligaciòn incumplida. El locadorpropietario de un inmueble, no se obliga a garantizar un determinado nùmero de ventas o de publico en la zona donde està ubicado el inmueble.

Pero en el shoping hay un nexo asociativo que se adosa a las relacione de cambio, de cesion de uso y goce que causa la locaciòn de cosas. Por esta razòn, se dijo en un fallo reciente, que no hay una obligaciòn de resultado ni de medios respecto del exito o fun cionamiento del negocio del shoping center, pero que hay una suerte comun compartida, de modo tal que tal resultado no es indiferente ${ }^{39}$.

Es evidente que la suerte es comùn, y de ahì la conexidad existente. Sin embargo, el buen o mal funcionamiento depende de todos los integrantes de la red, y no solo del organizador. De tal manera puede distinguirse:

- la actividad de cada uno de los integrantes de la red: por ejemplo, si los negocios que estàn en el shoping center no resultan atractivos, o tienen precios caros.

- la actividad de la empresa organizadora.

De tal manera que, salvo disposiciòn contractual no abusiva en contrario, la obligaciòn de la organizadora es desarrollar los medios conducentes para concretar la expectativa creada en la planificaciòn del emprendimiento comùn. Su incumplimiento culposo produce la obligaciòn de indemnizar los daños causados.

\section{Derecho a la estabilidad}

Las redes tienen como caracterìstica su duraciòn, y de ello se sigue una vocaciòn de estabilidad en la relaciòn. Este elemento tipifica no sòlo los aspectos extintivos sino tambièn el momento funcional.

Este derecho tiene su contracara en un deber de obrar de buena fe que se concreta en dos momentos:

? En la etapa de cumplimiento: no modificar intespestiva o injustificadamen te el vinculo, de modo que ello lleve a su desnaturalizaciòn. En la jurisprudencia se han establecido reglas en este sentido diciendo que "El contrato de concesión impone a la empresa concedente el deber secundario de evitar todo aquello que pueda frustrar el fin de la concesión o perjudicar indebidamente a la otra" ${ }^{40}$ : "... y en conse cuencia (...) evitar (..) cualquier modificación de las condiciones operativas del contrato, aun cuando dependan de la voluntad exclusiva de la concedente, deben ser motivo de una comunicación al concesionario, pues de lo contrario la situación aparece como injusta y arbitratria..."41.

? En la extinciòn: la necesidad de preavisar la extinciòn y no obrar de manera intespestiva, de modo de desbaratar los derechos de la otra parte.

\section{El deber de trato igualitario}

Cuando alguien puede establecer normas con eficacia general hacia terceros integrantes del grupo, como sucede en el contrato colectivo, en el contrato forzoso, en las condiciones generales de los contratos, o imponer costumbres obligatorias, con distinta intensidad y valor, su decisión impacta en el grupo y en la comunidad.

El juzgamiento del uso del derecho no puede ser mediante el examen de su interés, de la intención de dañar o de la culpa.

Necesariamente debe examinarse mediante la compatiblidad con los bienes públicos afectados y la noción de grupo.

Esta aparición de un derecho colectivo lo asemeja bastante a las facultades que tiene un legislador. También son similares los problemas puesto que tiene que compaginar intereses contrapuestos, tener una mirada global del universo a regular y examinar las consecuencias.

Por ello pensamos que, en el caso de analizar estas regulaciones, debe adoptarse un criterio particularmente estricto, adoptando el modelo de un buen legislador y exigiendo una previsibilidad mayor que la común en la contemplación del espectro de los resultados de las conductas normativas.

Podemos señalar, por los fundamentos predichos, que hay un principio demo crático aplicable a la organización del mercado que resulta comunicable a toda "situación jurídica" que emana de la autonomía privada.

En particular, en las redes contractuales, surge con claridad la obligatoriedad del organizador de establecer reglas genèricas e igualitarias.

40. CNCom., Sala B, 14/3/83, ED, 104-182.

41. CNCom., Sala A, 31/10/89, "Barragán, Juan H. c/Grimoldi, La Marca del Medio Punto S.A.", LL, 1990-D-228 
Por ejemplo, con relaciòn al contrato de concesiòn, se ha dicho que es una obligaciòn del concedente el trato igualitario para todos los concesionarios ${ }^{42}$. Ello no significa que todos sean iguales, sino que tengan igualdad de oportunidades, las que luego podràn ser aprovechadas desigualmente por cada uno de ellos.

\section{TERCERA PARTE:}

\section{Relaciones Externas}

\section{I) Efectos frente a terceros:}

\section{El problema}

En los casos que examinamos, hay un conflicto respecto del efecto relativo de los contratos. Hay dos o mas empresas que actuan en red, celebrando contratos diferentes y autonomos respecto de un tercero. Hemos dicho que desde el punto de vista del cliente que recibe una satisfaccion a traves de dos o mas contratos, los mismos se presentan como relacionados, y que se han utilizado las nociones de dependencia reciproca y de condicion para justificar algunos efectos.

El problema que se presenta es complejo y se da en muchos vinculos contractuales, tanto de consumo como discrecionales:

- Cuando una persona contrata la compra una heladera en una firma y obtiene un credito en otra indicada por ella, celebra dos contratos autonomos:

42. HOCSMAN, "Contrato de concesiòn comercial", De. La Rocca, 1994 mutuo y compraventa. Si la cosa presenta algun vicio, podra deducir su accion, pero debera seguir pagando porque no podra plantear esa cuestion en el mutuo celebrado. Lo mismo sucede cuando se compra con tarjetas de credito.

- Una empresa importa maquinarias y para ello celebra un contrato de compraventa, otro de transporte, otro de seguro, otro de asistencia tecnica, y muchos otros, de modo que el proposito practico no es el funcionamiento autonomo, sino coordinado de todos ellos. Sin embargo, el momento de conceder acciones, el Derecho no considera ese entrelazamiento.

En el derecho argentino, en ausencia de una disposicion legal especifica se han ensayado diversos fundamentos.

\section{Fundamentos juridicos}

A) La dependencia y el control:

A1) El caso de las obras sociales y de las clinicas

En estos casos, se produce una clara actuacion en red: las obras sociales, las clinicas, los medicos, se aunan en la prestacion frente al paciente, sin formar por ello, una sociedad. Son vinculos independientes, y ello ha motivado que la doctrina y jurisprudencia se ocuparan de establecer las bases del debito de responsabilidad, de uno, por el obrar del otro.
En este sentido, sostiene BUERES $I^{43}$ que la noción de dependencia puede ser comprendida con sentido lato, y se verifica cada vez que se confiera al auxiliar una autorización para obrar; quien la imparte tuvo al menos un "ocasional" poder de elección y posee un "virtual" poder de control y de impartir órdenes al autorizado. El ejecutor del último tramo de prestación es auxiliar o dependiente. De ello se sigue que "cuando los poderes de elección, contralor. dirección, etc, se diluyen hasta un punto en que ni siquiera acudiéndose a una ficción pudiera concebírselos en su existencia, aunque más no fuera que de un modo virtual, el deber "reflejo" o "indirecto" de garantía que estimo es objetivo por el actuar ajeno, deja de ser tal y da paso o se transforma, en un deber juridico de seguridad, que funciona con carácter secundario de la prestación principal y cuya trasgresión genera una responsabilidad directa del deudor".

La jurisprudencia se ha orientado ha declarar la responsabilidad de la obra social por los hechos danosos que causan los medicos cuando son dependientes de ella o, cuando no siendo dependientes, participan de un listado cerrado. Si es "cerrado" la obra social debe responder por el incumplimiento de la prestación de salud a su cargo y que la obra social delego en de- terminados sanatorios y profesionales. La obra social se valió de terceros para ejecutar su obligación, siendo los sustitutos determinados por ella, obstándole al afiliado el camino de la opción ${ }^{44}$.

\section{A2) El caso del franquiciante:}

El problema que se discute aquì es la responsabilidad del franquiciante por los hechos del franquiciado. Este supuesto encierra varias hipotesis disimiles, de las que recataremos una, que es particularmente ùtil para nuestros propòsitos.

En el caso especifico de la responsabilidad por daños, Kemelmajer de Carlucci se ha pronunciado por la afirmativa 45 señalando que "el control externo ejercido por el franchisor crea generalmente una relaciòn de subordinaciòn tècnica muy cercana a la dependencia que justificarìa la responsabilidad vicaria", y por ello no responde si no ha tenido ninguna posibilidad de contralor.

De tal modo, la dependencia y el control, son los fundamentos de la imputacion.

A-3- Dependencia tecnica: el caso del lavavajillas

En un caso jurisprudencial ${ }^{46}$, se trataba de una persona que habia com prado un lavavajillas, el que, luego de un

43. BUERES, Alberto, "Responsabilidad de las clinicas y establecimientos asistenciales", De. Abaco. Tambien su voto en fallo primera instancia "Sachi de Reggie, Teresa c. Altman Canestri, Edgardo". LL- 1981-D-132. CNCIV SALA D. "MACKINSON,JORGE C. WILK, ALFREDO".LL. 1983-B-554; idem en "ASTESIANO, ALBERTO C. POLICLINA BANCARIA 9 DE JULIO", LL. 1985-C-638. ; "Fernandez Russo, Miguel c. Hospital Jose Ramos Mejia". JA.-18-4-90.-; PESCIO, CESAR, 1 inst."SANCHEZ, PASCUAL C. MUNICIPALIDAD DE LACAPITAL".LL-1986-A-435.

44. Ampliamos en ntro libro "La empresa medica", Rubinzal y Culzoni, 1997.

45. "Daños causados por los dependientes", Hammurabi, pag 87

46. Causa "Baskir" fallada por la CNCOM SALA B, public en LL.6.6.96 
tiempo comenzo a producir algunas fallas pequenas. $\mathrm{Al}$ ser atendido por el servicio, se produjo una negligencia imputable este ultimo, que trajo como consecuen cia una inundacion en el departamento del actor.

El actor habia celebrado un contra to de locacion de servicios profesionales con el "service" y se habia producido un incumplimiento culposo de parte de este ultimo, que derivaba en su responsabili dad contractual. Sin embargo, demanda tambien al vendedor, con quien habia ce. lebrado un contrato de compraventa, e que se hallaba cumplido perfectamente. No habia vinculacion entre ambos contra tos porque:

- en el primero se trataba de una locacion de servicios y en el segundo de una compraventa.

- en el primero hay una obligacion de hacer y en el segundo una obligacion de dar.

- los obligados son personas juridicas distintas.

- solo existio un incumplimiento de la obligacion de hacer, pero no de la de dar.

Sin embargo, ocurrio en el caso que la empresa vendedora indicaba al cliente que para la atencion de cualquier desperfecto, debia recurrir al service indicado por ella. No existia en este caso una dependencia laboral del service respecto de la empresa vendedora, ni una sociedad $n$ vinculo asociativo. Solo existia un interes economico de ambos de contrata agrupadamente con los clientes, obteniendo asi beneficios mutuos.
Probablemente el service no tenia la solvencia necesaria para afrontar los danos sufridos por el actor, y por esta razon se demando al vendedor.

Para encontrar una vinculacion entre el vendedor y el service frente al cliente, la sentencia juzgo que habia una "dependencia tecnica".

\section{La regla: mayor control, menor eleccion, mayor responsabilidad.}

En los casos precedentes se observa que la libertad de eleccion de uno de los contratantes, es absorbida total o parcialmente por el otro:

- En los contratos medicos, cuando la obra social establece un sistema cerrado, limita la libertad de eleccion del paciente.

- En el caso del lavavajillas, el fabricante que indica un service determinado, limita la libertad del comprador de elegirlo.

- En el contrato de franquicia, el control es la esencia del vinculo, pero se transforma en dominacion cuando se absorben las facultades de eleccion del tomador de modo tal que frente al tercero, no hay distingos.

Puede establecerse entonces que, a mayor control ejercido una de las partes, hay una correlativa disminucion del poder de eleccion de la otra.

El aumento del control se hace normalmente, porque mejora la posicion economica y estrategica de una de las partes en el contrato, obteniendose asi beneficios. Naturalmente, estos beneficios deben ser complementados con los costos asociados, y es alli donde ingresa la regla de responsabilidad.

Normalmente, el riesgo derivado del ejercicio de la libertad de eleccion es soportado por quien lo ejerce. Si una persona elige a un medico y se equivoca porque es uno de mala calidad, carga con el peso de esta decision erronea. Usualmente es una regla admitida ${ }^{47}$ ya que hay buenos y malos oferentes, y la seleccion se opera mediante el intercambio de decisiones en tre los individuos.

Cuando la obra social se interpone entre el paciente y el medico como agente financiero, puede absorber esta libertad de eleccion del paciente. El agente financiero del sistema advierte que no puede mantener esa libertad, porque el costo es demasiado alto. Si el paciente puede elegir entre todos los medicos que estan ofreciendo sus servicios, se produce un incremento de costos que la obra social no puede soportar. Consecuentemente limita el numero de oferentes de servicios, estableciendo una cartilla. De este modo limita sus costos, porque la cantidad de profesionales es controlable y puede celebrar arreglos contractuales con ellos, manteniendolos dentro de sus posibilidades economicas.

Esta es una circunstancia razonable dentro del esquema de funcionamiento de la Obra Social en el sistema legal actual.

La traslacion de la libertad de eleccion contractual desde el paciente hacia la obra social es clara, y tiene un efecto preciso, cual es la traslacion de los riesgos. No se puede absorber la libertad de eleccion sin asumir tambien los riesgos que ella acarrea.

De ello se sigue que si la obra social elige los oferentes y lo hace mal, ella debe soportar el riesgo. No se admite en cambio que el paciente pierda la libertad de eleccion en favor de la obra social y mantenga la carga de los riesgos, porque ello importa una falta de equilibrio en su relacion con la obra social.

\section{B) Expectativa juridica y} Deberes colaterales:

El mandato dado voluntariamente 0 la apariencia juridica creada frente a terceros es un factor imputativo. Se trata de una conducta del comitente presunto que ha permitido que se genere una expectativa frente al damnificado de buena $\mathrm{fe}^{48}$.

Con mucha fuerza, señalada por Alterini ${ }^{49}$, surge la responsabilidad del productor aparente, de quien pone la marca en un producto y crea una expectativa. Segùn Alterini, es el riesgo-provecho que obtiene alguien de esa apariencia, el fundamento mediato de la imputaciòn.

\section{B1) La ley de proteccion de los con-} sumidores

En el articulo 40 de la ley 24240 , se preveia la solidaridad de todos los integrantes de la cadena de comercializacion, lo que fue vetado por el Poder ejecutivo nacional.

47. FRIED, Charles, "Contract as a promise. A Theory of contractual obligation", Harv. Univ Press, 1981.

48. KEMELMAJER DE CARLUCCI, Aida, op cit, pag. 93

49. Alterini Atilio, "Responsabilidad objetiva derivada de la generaciòn de confianza", en "Derecho de Daños", 539 
No obstante ello, muchas obligaciones de origen legal, son imputadas a varios sujetos integrantes de la red. Asi,en la definicion misma del articulo primero, quedan obligadas: "todas las personas fisica o juridicas que en forma profesional, aun ocasionalmente, produzcan, importen, distribuyan o comercialicen cosas o presten servicios a consumidores o usuarios".

Con referencia al deber de informar, el artìculo 4 obliga a quienes produzcan, importen, distribuyan o comercialicen co sas o presten servicios".

El articulo 5 establece que las cosas y los servicios deben suministrados o prestados...de forma tal que no presenten peligro. El articulo 6 dispone que las cosas y servicios cuya utilizaciòn pueda suponer un riesgo, deben comercializarse observando los mecanismos,instrucciones...paar garantizar la seguridad de los mismos".

Ello da lugar a que muchos deberes colaterales, puedan ser imputados a diversos integrantes de la red, con fundamento en la legislacion mencionada, y que pueden ser una fuente de responsabilidad hacia ter ceros.

Veamos los ejemplos.

B2) Expectativa juridica creada:El caso de los hipermercados

En este ambito es particularmente interesante la problematica suscitada en relacion a los hipermercados, que examinaremos seguidamente.

Es habitual que la empresa organizadora del hipermercado actùe como agente de todos los integrantes del mismo para la contrataciòn de un seguro contra los daños sufridos por incendios o robos. En este caso asume voluntariamente un deber de prevision y de proteccion respecto de quienes son locatarios. Este debito no fluye naturalmente del contrato de locacion ni esta contemplado en el derecho supletorio (normativa del Codigo Civil referida a los contratos de locacion). La racionalidad economica no se basa en un contrato de locacion, sino en una pluraridad de ellos, ya que la empresa, al actuar como agente de numerosos locatarios frente al asegurador, obtendra precios mas baratos en el contrato de seguro de incendio. En muchos supuestos, el asegurador impone como contrapartida, la adopcion de medidas de seguridad, que no son tomadas por los locatarios, sino por la empresa organizadora.

Llegados a este punto, se puede observar con claridad que la empresa ha asumido obligaciones de prevencion e incendio y de contratacion del seguro correspondiente, que no forman parte normal del contrato de locacion. Se trata sin embargo de una conducta que da lugar a una expectativa juridica (arts 919 y 1146 Codigo Civil Arg) en virtud de la cual, tanto los locatarios como el asegurador, esperan que la empresa se ocupe de la prevision y del aseguramiento.

Existe aqui la asuncion voluntaria de un deber colateral de prevision.

En otros casos, se han deducido deberes colaterales respecto de terceros de origen legal. Es el caso de la responsabilidad de la empresa organizadora del hipermercado por los hurtos de automòviles que ocurren en las playas de estacionami- ento, y que ha dado lugar a soluciones contradictorias.

Advièrtase la complejidad del problema: una persona va a comprar una corbata a un negocio del hipermercado y deja el automòvil en la playa de estacionamiento, la que es ofrecida por la empresa en forma gratuita. Podrìa decirse que celebrò dos contratos, uno de compraventa y otro de depòsito, o bien que celebrò uno de compraventa que lleva conexo el ofrecimiento de la playa de estacionamiento, o bien que celebrò un contrato de compraventa y no hay ninguna relaciòn con la empresa organizadora del shoping y propietaria de la playa.

En un caso $^{50}$ el Tribunal entendiò que en la situación examinada, el ingreso y egreso de los rodados era libre y gratuito, y se estacionaba en el lugar elegido durante el tiempo deseado. El usuario cierra su rodado conservando las llaves, al egresar no existe control ni verificación. En su opinión, no se dan las circunstancias caracterizantes del contrato de garaje y no puede sostenerse que haya mediado depósito civil, habida cuenta de que no medió entrega de la cosa al supuesto depositario, con el fin de que éste asuma la obligación de guarda sobre ella o de restituirla en el mismo estado ( arts. 2182 y 2190, Cód. Civ.).

En otro caso la soluciòn fue distin$\mathrm{ta}^{51}$, porque se entendiò que la absoluta falta de control en la entrada y salida de los vehículos en realidad constituye una negligencia por parte de la empresa organizadora.

50. Cám. Nac. Com., sala B, "Argos Cla. Argentina de Seguros Generales S.A. c/ Carrefour Argentina S.A.", J.A., 1992-II-59 51. Cám. Nac. Com., sala E, "Inca S.A. Cía de Seguros $c /$ Carrefour Argentina S.A.", 28-10-91, J.A. 1992-11-60
No hay contrato entre el consumidor y el organizador del shopping center referido a la playa de estacionamiento. Sin embargo, èsta es ofrecida por la empresa para facilitar la compra, para inducir a ella, para marcar diferencias con la competencia.

De tal modo estamos en la antesala de un contrato, en el que se plantean dos opciones legales. Puede señalarse que se trata de una conducta social tìpica que produce una responsabilidad "antecontractual", o bien que es parte de una oferta compleja efectuada por el organizador. En ambos casos, la soluciòn es la misma, en la medida en que existe una obligaciòn de seguridad, sòlo que en el primer caso serìa extracontractual, mientras que en el segundo es contractual. Sin embargo, con cualquiera de las dos fundamentaciones caerìa dentro de la ley de protecciòn de los consumidores y usuarios (ley 24240).

En todos estos casos puede advertirse que existen deberes colaterales: de informacion, de prevision, de proteccion, $y$ otros, que con fundamento en la proteccion del consumidor o en la expectativa juridica creada, se imponen a quien no es contratante directo, sino integrante de una red de prestacion.

\section{C) Existencia de una condicion} tacita:

En otros casos, puede encontrarse el fundamento en la existencia de una condicion tacita. 
Es cierto que habitualmente, las par tes no celebran expresamente estos pactos, pero tambien lo es que la condicion puede surgir tacitamente cuando aparece con su ficiente seguridad que tal ha sido la intencion de las partes ${ }^{52}$

Habra que estar entonces a la interpretacion de la voluntad de las partes para determinar si la reciprocidad o la condicion han sido consideradas como modalidades de los contratos celebrados.

\section{Efectos}

En cuanto a los efectos que produciria la referida reciprocidad, son de interpretacion restrictiva, puesto que son una excepcion a la regla del efecto relativo de los contratos. Entre ellos, en el derecho comparado se han senalado los siguientes:

- las viscisitudes que afectan a un contrato (invalidez, ineficacia, resolucion),

- el pacto comisorio o la excepcion de incumplimiento contractual podrian ser invocados si uno de los contratos no ha sido cumplido.

- la accion directa en materia de responsabilidad.

\section{Situaciones juridicas abusivas}

En numerosas redes contractuales se pueden crear mercados cautivos lesivos del ejercicio de facultades de individuos. Ello puede repercutir sobre otros.

es frecuente en grupos de ahorro y prestamo, tarjetas de credito, sistemas de medicina prepaga, agrupamientos contractuales de propietarios de propiedad horizontal, clubes de campos, o sistemas de tiempo compartido.

La conexidad contractual puede dar lugar a la creacion de un cumulo de derechos que permiten una accion concertada. Cuando ello es impeditivo o limitativo de las facultades de otro contratante, puede dar lugar a situaciones juridicas abusivas, con la consiguiente aplicacion de a sancion juridica frente al acto abusivo ${ }^{53}$

\section{Conexidad contractual y obligaciones conexas o concurrentes:}

En muchos casos, fundado en la res ponsabilidad por daños, el legislador impu ta a una cadena de responsables. En el caso de la locacion de obra, pueden responder el locador, y otros sujetos, pero se trata de obligaciones concurrentes. Las obligaciones conexas se caracterizan porque hay un mismo acreedor, una identidad de objeto pero varios acreedores cuyas obligaciones tienen distintas causas. La accion de repeticion entre ellos se funda en esa cau$\mathrm{sa}^{54}$.

Aunque se denominan tambien conexas, se trata de un elemento que afecta a las obligaciones y no directamente a los contratos.

52. CAZEAUX-TRIGO REPRESAS, "Derecho de las Obligaciones", Lep, 1975, $t$ II, pag 188

53. Ampliamos en .LORENZETTI, Ricardo, "Nuevas fronteras del abuso del derecho-Situaciones juridicas lesivas de libertades. Tutela del mercado y amparo", LL. 1995-E-593.

54. CAZEAUX-TRIGO REPRESAS, "Derecho de las obligaciones", Lep, t.2, pag. 80; LLAMBIAS, JJ, "Tratado de Derecho CivilObligaciones", Abeledo Perrot, Bs.As., 1982, T II-A- pag 589.

\section{II) Efectos frente al mercado: Las redes y el derecho de la competencia}

El Mercado, en un sentido amplio, es "cualquier conjunto de mecanismos mediante los cuales los compradores y vendedores de un bien entran en contacto para comerciarlo" . Mas especificamente, es un modo de asignacion de recursos escasos, que se basa en el intercambio voluntario de los mismos, producido por los agentes economicos a traves de la oferta y la demanda. El Mercado se presenta entonces, como un instrumento de planificacion economica descentralizada. El esquema distributivo final no es previsto ex ante, como en la planificacion centralizada, sino que surge ex post, como derivado de la interaccion compleja de conductas economicas. En virtud de ello, tiene como caracteristica metodologica, su flexibilidad a los cambios ya que es hipersensible a las influencias internas o externas, y ademas, que la distribucion final esta sometida a riesgo, siendo impredecible.

De alli surge un elemento esencial: el precio es un dato objetivo, externo a la actividad empresaria; no se lo conoce de antemano ni se lo puede determinar.

Es natural que los agentes economicos intenten disminuir este riesgo. Por esta razon pueden constituir grupos fuertes que se impongan a los debiles y disminuyan la competencia, y por lo tanto aseguren algunas de las variables que escapan normalmente a su control. En este sentido, el monopolio surge cuando el unico vendedor de un producto o servicio puede imponer precios; el monopsonio se presenta cuando hay un unico comprador. En ambos casos, al existir un unico oferente 0 demandante, existe un poderio que distorsiona el funcionamiento del mercado.

En otros casos, se realizan acuerdos para fijar precios, ganancias, o bien limitar la produccion para generar escasez $y$, consecuentemente mayor demanda e incremento de precios. Estos son acuerdos colusorios en tanto limitan la competencia entre las empresas y perjudican el libre funcionamiento del mercado 55 .

Las redes pueden ser vistas como acuerdos para la violaciòn de las reglas que protegen la libre competencia. Este tema ha surgido principalmente en relaciòn a la franquicia, porque es lel sistema de redes que exhibe mayor grado de integraciòn. •

Planteado el problema, examinaremos primero las prohibiciones y luego si las redes constituyen violaciones a las mismas.

\section{Las conductas punibles}

La ley 22.262 de defensa de competencia de1.980, tutela el "interes economico general" (art. 1ro. in fine), y prohibe "los actos o conductas relacionadas con la produccion e intercambio de bienes y servicios, que limiten, restrinjan o

55. Sobre la competencia conf: CABANELLAS, Guillermo, "Derecho antimonopolico y de defensa de la competencia", Heliasta, Bs. As. 1983. REYES y otros, en "Derecho de la competencia", Revista de Derecho Industrial, enero-abril, 1993, Depalma, Bs As: BS.As. RIPPE, Slegber, "El dection Pega 255; HOLZ, Eva "Mercado y Derecho", Fundacion de cultura Universitaria, Montevideo, Montevideo, 1993, ULHOA COELHO, Fabio, "Direito Antitruste brasilerio", Saraiva, 1995.

Revista da Faculdade de Direito da UFRGS, v. 16, 1999

Revista da Faculdade de Direito da UFRGS, v. 16, 1999 
distorsionen la competencia o que constituyan abuso de una posicion dominante en un mercado, de modo que pueda resultar perjuicio para el interes economico general". Aclarando este concepto señala (art.41), "...que una persona goza de una posicion dominante en un mercado cuando para un determinado tipo de productos o servicio es la unica oferente o demandante dentro del mercado nacional o, cuando sin ser la unica, no esta expuesta a una competencia sustancial". Asimismo, indica (art. 41 inc. b) que "dos o mas personas gozan de posicion dominante en un mercado cuando para un determinado tipo de producto o servicio no existe competencia efectiva entre ellas, o sustancial por parte de terceros, en todo el mercado nacional, o en una parte de el". La ley (art. 41) indica como conductas punibles: fijar, determinar o hacer variar los precios en un mercado; limitar o controlar el desarrollo tecnico o las inversiones destinadas a la produccion, distribucion o comercializacion de los mismos; establecer las condiciones de venta y comercializacion, cantidades minimas, descuentos y otros aspectos de la venta y comercializacion; subordinar la celebracion de contratos a la aceptacion de prestaciones $\mathrm{u}$ operaciones suplementarias ajenas a esos acuerdos; celebrar acuerdos entre competidores distribuyendo zonas o mercado; impedir el acceso a competidores; negarse a satifacer pedidos; imponer discriminaciones en la compra o venta de bienes; destruir producciones; abandonar cosechas; comunicar a los competidores precios o condiciones de venta."
La sola lectura de estas disposiciones muestra que las redes constituyen sistemas que pueden producir los efectos que la norma prohibe.

\section{Las redes de franquicia}

La red de franquiciantes podrìa ser considerada como un acuerdo para fijar un precio, o controlar la distribucion y comercializacion de bienes y servicios o para la distribucion de zonas. No obstante lo expuesto, en general se considera que las redes de franquicia no producen por su sola existencia una violaciòn del derecho de la competencia.

\section{Ello es asì porque:}

? no se trata de un acuerdo entre competidores, porque la franquicia se conforma cuando un negociante exitoso intenta reproducirlo incorporando a otras personas que no eran comerciantes competidores ${ }^{56}$

? el sistema de franquicia no es un es una fusion sino una cantidad de contratos conectados. La conexidad contractual se da en virtud de una finalidad económica general que los relaciona, pero no es un acuerdo cuya finalidad sea anticoncurrencial.

? La red en sì misma no impide la existencia de otros oferentes en el mercado.

Estos sòlidos argumentos inhiben la monopolio o un acuerdo colusorio. Sin grupo, sino una red, lo que implica que no posibilidad de calificar a la red como un

56. Manago, Jose Antonio, Franchising y defensa de la competencia, La Ley, 16/6/93 embargo, pueden existir distorsiones, efectuadas a travès de clàusulas, que den origen a violaciones.

\section{Clausulas que lesivas del derecho anticoncurrencial}

En el derecho comparado la jurisprudencia se ha orientado al anàlisis de clàusulas $\mathrm{o}$ acuerdos en particular, efectuados por los integrantes de la red, o impuestos por quien la organiza, y que resultan lesivos del derecho anticoncurrencial.

Uno de los aspectos màs importantes es el acuerdo de fijaciòn de precios. Habitualmente es una decisiòn del organizador de la red que sugiere, o impone, directa o indirectamente el precio final. En favor de la legitimidad de esta decisiòn se señala que es un derecho del franquiciante porque se trata de bienes de su autoria, invencion o propiedad industrial o intelectual, y puede fijar su valor. Ademas, el establecimiento de "un precio asegura su uniformidad en los distintos puntos de la cadena, lo que la hace aparecer como seria." ${ }^{57}$

Otra de las cuestiones es la relativa a la organizaciòn geogràfica de la red, que puede ser vista como un reparto de mercados. En favor de la legitimidad de la red, se ha dicho que la conformaciòn no importa un acuerdo colusorio, porque se hace una oferta al publico indeterminado, con disponibilidad de zonas, y quienes ingresen al sistema van ocupando los espacios

\section{Manago, Jose Antonio, op cit.}

58. RUIZ PERIS, Juan Ignacio "EL CONTRATO DE FRANQUICIA Y LAS NUEVAS NORMAS DE DEFENSA DE LA COMPETENCIA", Editorial Cívitas, Madrid, 1991 disponibles de acuerdo a su eleccion y segun su propia conveniencia, no pudiendo el franquciante obligarlo a ocupar una zona determinada. De ello surge que en el sistema de franchising no existen acuerdos o acciones concertadas para distribuir, entre competidores, zonas que el franquiciante determina en su cadena, sin intervenir en los negocios de la competencia ni celebrar acuerdos espureos de manipulacion del mercado.

En el àmbito de la Union Europea ${ }^{58}$, existe el conocido caso "Pronuptia de Paris $\mathrm{GmbH}$, Frankfurt am Main vs. Pronuptia de Paris Irmgard Schillgallis, Hamburg" del 28 de enero de 1.986, en el cual la Corte de Justicia de la Comunidad Europea fue llamada a decidir sobre la interpretacion del art. 85 del Tratado de Roma y del Reglamento 67/67 de 122 de marzo de 1.967 dictado por la Comision de las Comunida des Europeas, concerniente a la aplicacion del art. 85, parr. 3ro. del Tratado, a ciertas categorias se trataba de una franquicia de distribucion. El litigio se planteo entre la sociedad Pronuptia de Paris, de Franckfurt, filial de una sociedad francesa del mismo nombre, y la señora Schillgallis, de Hamburgo, que explotaba un negocio bajo la enseña "Pronuptia de Paris". El litigo se centro en la obligacion por parte del franquiciado de pagar al franquiciante con efecto retroactivo un porcentaje sobre sus cifras de ventas. El tribunal estableciò que:

- "las clausulas que resulten indispensables para evitar que el "saber 
hacer" transmitido (know-how) y la asistencia aportada por el franquiciante sean aprovechadas por la competencia, no constituyen practicas restrictivas de la competencia en el seno del art. 85, parr. 1ro."

- las clausulas que organizan el control indispensable para preservar la identidad y reputacion de la cadena que esta simbolizada por la enseña, no consituyen de ningun modo restricciones a la competencia en el sentido del art. 85 parr 1 ro.

? "las clausulas que representen una division y reparto de los mercados entre franquiciante y franquiciado, o entre franquiciados, constituyen restricciones a la competencia en la interpretacion de la misma norma;"

Este enfoque, a nuestro juicio correcto, parte de la premisa de que la red no es por su sola existencia violatoria de derecho protectorio de la competencia en el mercado. Sobre esta base, hay que examinar claùsulas especìficas que como, las que de acuerdo de precios, constituyen restricciones a la libre competencia.

Una de las estipulaciones del contrato de franquicia que ha provocado litigiosidad en cuanto a su ilicitud a la luz de la normativa "antitrust" es aquella que permite al franquiciador seleccionar a los franquiciados, ya sea en base a determinados criterios previamente establecidos o a mero acuerdo del franquiciador e incluso de los franquiciados existentes en el área geográfica. Este tipo de cláusulas han sido analizadas por la jurisprudencia "antitrust" norteamericana como un supuesto de negativa de venta o negativa a contratar, considerando por tanto legitimas. Sólo en aquellos casos en que la negativa es parte de un boycot, que tenga como finalidad excluir una firma del mercado, estarán prohibidas $^{59}$.

Otro de los tipos de estipulaciones que plantean dudas acerca de su licitud en el contrato de franquicia son las que determinan un reparto geográfico de mercados entre los distintos franquiciados y aun entre éstos y el franquiciador con el consiguiente reparto de la clientela. La jurisprudencia norteamericana ha considerado la legitimidad de este tipo de cláusulas si persigue la protecciòn de los los signos distintivos del franquiciador que el franquiciado usa en su establecimiento, porque exigir al franquiciado vender solamente los productos designados por el franquiciador o prohibirle vender productos no compatibles, dada la necesidad de preservar el interés legítimo de éste al mantenimiento del crédito de una marca.

\section{Direitos Fundamentais no Estado Constitucional Democrático}

Para a relação entre direitos do homem, direitos fundamentais, democracia e jurisdição constitucional

$$
\text { Robent EAlexy*, EKiel-OHemanha }
$$

Tradutor: Dr. Luís Afonso Heck - Prof. na UFRGS e ULBRA

\section{RESUMO}

artigo ocuba-se primeiro com os três problemas dos direitos do homm Depois

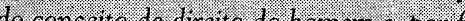
, por $f \mathrm{~m}$, anal Cos nocracia e a jurisdição constitucional.

\begin{tabular}{|l}
\hline \multicolumn{1}{|c|}{ SUMÁRIO } \\
I. Os três problemas dos direitos do ho- \\
mem. \\
1. Os problemas epistemológicos. \\
2. Os problemas substanciais. \\
3. Os problemas institucionais. \\
II. O conceito de direito do homem. \\
1.Direitos universais. \\
2.Direitos morais. \\
3.Direitos preferenciais. \\
4.Direitos fundamentais. \\
5. Direitos abstratos. \\
III. Direitos fundamentais, democracia e \\
jurisdição constitucional. \\
1. Quatro extremos. \\
2. Três modelos. \\
3. Representação politica eargumenta- \\
tiva.
\end{tabular}

Revista da Faculdade de Direito da UFRGS, v. 16, 1999
Passaram-se, hoje quase no dia, exatamente 50 anos desde que a Assembléia Geral das Naçōes Unidas votou a Declara ção Universal dos Direitos do Homem em 10 de dezembro de 1948. Nisto, não se tratou de alguma das numerosas resoluções das Nações Unidas. Norberto Bobbio qualificou acertadamente a Declaração Universal dos Direitos do Homem como a "até agora maior prova histórica para o 'consensus omnium gentium' com respeito a um sistema de valores determinado". ${ }^{1}$ Que se tratava de um consenso sobre valores fundamentais de significado eminente estava claro ao 48 Estados então representados na Assembléia Geral. O preâmbulo exprime isso impressionantemente pelo fato de qualificar os direitos do homem "como o ideal comum a ser alcançado por todos os povos e nações". Com isso, estão claramente

Palestra inaugural da comemoração dos cem anos da Faculdade de Direito da UFRGS, proferida no dia 9 de dezem bro de 1998 no Salăo Nobre da Faculdade de Direito da UFRGS.

1. Norberto Bobbio, Das Zeitalter der Menchenrechte, Berlin 1998, S. 9. 